\title{
Regional Minimum Wage and the Increase in the Personal Exemption
}

\author{
Solihin Makmur Alam \\ Faculty of Economics, Bina Nusantara University, Jl. K. H. Syahdan No. 9, \\ Kemanggisan/Palmerah, Jakarta Barat,11480, Indonesia. Telephone +62.215345830. \\ E-mail: renyswani@gmail.com
}

\begin{abstract}
The policy of the Central Government raised the limit on Income Not Taxable (PTKP) in 2013 aims to reduce the income tax burden on workers. At the same time, local governments also raise the Regional Minimum Wage (UMR) in 2013 to customize it with the level of inflation and rising prices. Some people think that the policy of the Central Government to improve the welfare of workers by doing adjustments on PTKP is useless because in fact the increase coincided with increases in PTKP UMR. In 2013, almost all local governments set the UMR under PTKP. Thus, the workers who work in these areas did not have to pay income tax. This condition does not apply to workers who work in areas that have the above PTKP UMR. The workers who work in these areas will not receive earnings as a whole. Thus, the income tax has reduced the level of their well-being.
\end{abstract}

Keywords: income not taxable, tax burden, regional minimum wages

JEL Classification: J31, J51

\section{Upah Minimum Regional dan Kenaikan Pendapatan Tidak Kena Pajak}

\begin{abstract}
Kebijakan Pemerintah Pusat menaikkan batasan Penghasilan Tidak Kena Pajak (PTKP) di tahun 2013 bertujuan untuk mengurangi Beban Pajak Penghasilan pekerja. Pada waktu yang bersamaan, Pemerintah Daerah juga menaikkan Upah Minimum Regional (UMR) di tahun 2013 untuk menyesuaikannya dengan tingkat inflasi dan kenaikan harga. Sebagian masyarakat berpikir bahwa kebijakan Pemerintah Pusat untuk meningkatkan kesejahteraan pekerja dengan melakukan penyesuaian atas PTKP adalah sia-sia karena pada kenyataannya kenaikan PTKP ini bersamaan dengan kenaikan UMR. Pada tahun 2013 hampir seluruh Pemerintah Daerah menetapkan UMR di bawah PTKP. Dengan demikian, para pekerja yang bekerja di daerah-daerah tersebut memang tidak perlu membayar Pajak Penghasilan. Kondisi ini tidak berlaku bagi para pekerja yang bekerja di daerah-daerah yang memiliki UMR di atas PTKP. Para pekerja yang bekerja di daerah-daerah ini tidak akan menerima Penghasilan secara utuh. Dengan demikian, Pajak Penghasilan telah mengurangi tingkat kesejahteraan mereka.
\end{abstract}

Kata kunci: pendapatan tidak kena pajak, beban pajak, upah minimum regional

Klasifikasi JEL: J31, J51

\section{Introduction}

Considering the economic growth and monetary change in Indonesia recently and monitoring the rapid increment of living cost in the society, the Indonesian Central Government decided to adjust the limit of Personal Exemption of the
Individual Taxpayers. On 22 $2^{\text {nd }}$ October 2012, the Central Government through the Minister of Finance released the regulation regarding Adjustment of the Limit of Personal Exemption of the Individual Taxpayers through the Minister of Finance Regulation No. 162/ PMK. 011/2012. This Regulation is effective on $1^{\text {st }}$ 
January 2013. In coincidence with the issuance of that Regulation, all Indonesian Local Governments, whether in the Provincial, Regency, or City Level, also stipulate the Regional Minimum Wages which comes into effect on $1^{\text {st }}$ January 2013. The policy reason behind the increment of the Regional Minimum Wages is to adjust the workers' wages in the region with the Proper Living Standard in each Province, Regency, or City. Therefore, the reason of the Central Government to increase the limit of Personal Exemption in the national level and the reason of the Local Government to increase the Regional Minimum Wages in the local level are aimed to increase the welfare of the workers in general. This research is intended to find out how much the Regional Minimum Wages in Indonesia in 2013 and their corresponding Income Tax burden, and does the Central Government's policy in the national level and the Local Government's policy in the local level effective to increase the workers' welfare in each region.

\section{Methodology}

The methodology used in this research is Secondary Data Analysis. The Secondary Data gathered from this observation is the Regional Minimum Wages in 2013, set by the Local Government whether in the Provincial, Regency, or City Level. The population involves in this observation including 27 Provinces and 125 Regency / City in Indonesia that release their Regional Minimum Wages to public through their official website, newspaper, electronic news, and also to the Ministry of Manpower and Transmigration officially. The cut-off date for data gathering is as of $31^{\text {st }}$ December 2012. Thus, any change or amendment of the Regional Minimum Wages beyond that date is out of scope of this research.

As known that Indonesia has 33 Provinces. In relation to the Regional Minimum Wages, there are 6 (six) Provinces set their Regional Minimum Wages not in the Provincial level instead of in the Regency / City level. Those 6 (six) Provinces are West Java, Banten, Central Java, Yogyakarta Special Administrative Region (SAR), East Java, and Bali.

In connection with the increment of the limit of Personal Exemption and the Regional Minimum Wages, the level of the workers' welfare is assumed inversely proportional to the Income Tax. The Income Tax mentioned in this research is Income Tax Article 21 that is equal to the Payroll Tax that the workers need to pay to the Central Government through withholding mechanism by their employer. The higher the Income Tax that the workers need to pay, the lesser their wages' take home pay amount would be. In this sense, the Income Tax has negative impact upon their welfare. The Lesser the Income Tax that the workers need to pay, the higher their wages' take home pay amount would be.

In relation to the limit of Personal Exemption, the Central Government gives exemption based on the status of the Taxpayers whether s/he is unmarried with no dependent, married with no dependent, unmarried with dependent, or unmarried with dependent. In order to simplify this observation, it is assumed that the workers in this research are unmarried Taxpayers with no dependent.

\section{Results of Observation}

Based on data gathering as of $31^{\text {st }}$ December 2012, the Regional Minimum Wages that come into effect in 2013 in Indonesia is as follows. See table 1 in the Appendix.

In order to calculate the workers' annual Gross Income amount, the monthly Regional Minimum Wages as presented in Table 1 shall be multiplied by 12 (twelve) months plus 1 (one) month obligatory religious allowances (THR) set under the Minister of Manpower and Transmigration's Regulation. Therefore, the workers' annual Gross Income amount in 2013 is as follows. See table 2 in the Appendix.

The Minister of Finance Regulation No. 162/PMK.011/2012 dated 22 ${ }^{\text {nd }}$ October 2012 regarding Adjustment of the Limit of Personal Exemption of the Individual Taxpayers that comes into effect on $1^{\text {st }}$ January 2013 stipulates that the amount of Personal Exemption for Individual Taxpayers is as follows. See Table 3.

Furthermore, according to Article 21 paragraph (3) of the Income Tax Law No. $7 /$ 1983 as amended lately by Law No. 36 / 2008, in order to calculate the Assessable Income of 
Jurnal Ekonomi Pembangunan, 15 (2), Desember 2014, 172-190

Table 3. Limit of Personal Exemption in 2013

\begin{tabular}{clr}
\hline No. & \multicolumn{1}{c}{ Status } & $\begin{array}{c}\text { Personal Exemption in a } \\
\text { Year (Rp.) }\end{array}$ \\
\hline 1 & Unmarried Taxpayer & $24,300,000$ \\
2 & Additional for a Married Taxpayer & $2,025,000$ \\
3 & $\begin{array}{l}\text { Additional for a Working Wife whose Income is combined with Her } \\
\text { Husband's Income }\end{array}$ & $24,300,000$ \\
4 & $\begin{array}{l}\text { Addition for Each Dependent of Blood Relatives and Relatives by } \\
\text { Marriage in Straight Lineage, and Adopted Children (Maximum 3) }\end{array}$ & $2,025,000$ \\
\hline
\end{tabular}

Permanent Employee, the total Gross Income shall be deducted by Official Expenditure (that is stipulated by the Minister of Finance Regulation) Less the Personal Exemption. Moreover, Article 1 paragraph (1) of the Minister of Finance Regulation No. 250/PMK. 03/2008 dated 31 December 2008 regarding The Amount of $\mathrm{O}$ fficial Expenditure that can be deducted from the Gross Income of the Permanent Employee as stated in Article 21 paragraph (3) of the Income Tax Law, stipulates that the amount of the Official Expenditure shall be 5\% (five percent) from the Gross Income at the maximum of Rp. $6,000,000.00$ (six million rupiah) per year or Rp. 500,000.00 (five hundred thousand rupiah) per month. Based on those regulations, the formula to calculate the Assessable Income of the workers in Indonesia is as follows.

Assessable Income $=$ Gross Income Official Expenditure - Personal Exemption

Net Income $=$ Gross Income - Official

Expenditure
Assessable Income $=$ Net Income -

Personal Exemption

According to the aforementioned Minister of Finance Regulation and based on the data in Table 1, 2, and 3, the Assessable Income of unmarried workers with no dependent who work in the 27 Province and 125 Regency / City in Indonesia in 2013 is as follows. See Table 4 in the appendix.

From Table 4, it is clear that from 152 regions in Indonesia, only 12 regions that have Regional Minimum Wages subject to Income Tax. The rest of 140 regions, their Regional Minimum Wages are not subject to Income Tax. In relation to Income Tax, Article 21 paragraph (5) of the Income Tax Law explains that in order to calculate the amount of Income Tax Payable, the Tax Rate as intended in Article 17 paragraph (1) letter a shall be applied on the Assessable Income as intended in Article 21 paragraph (1), except otherwise stipulated by the Government Regulation. According to Article 21 paragraph (1) of the Income Tax Law, the Assessable Income subject to Income Tax under Article 21 is Income in connection with Employment, Services, or Works in

Table 5. Tax Rate on Income of Domestic Individual Taxpayers

\begin{tabular}{clc}
\hline No. & \multicolumn{1}{c}{ Taxable Income Tax Brackets } & Tax Rate \\
\hline 1 & Rp. 50,000,000.00 (fifty million rupiah) or less & $5 \%$ \\
2 & Over Rp. 50,000,000.00 (fifty million rupiah) to Rp. 250,000,000.00 (two & $15 \%$ \\
& hundred fifty million rupiah) & $25 \%$ \\
3 & Over Rp. 250,000,000.00 (two hundred fifty million rupiah) to Rp. & $30 \%$ \\
\hline & 500,000,000.00 (five hundred million rupiah) & Over Rp. 500,000,000.00 (five hundred million rupiah) \\
\hline
\end{tabular}




\section{Jurnal Ekonomi Pembangunan, 15 (2), Desember 2014, 172-190}

whatever name and form, received by Domestic Individual Taxpayers. Furthermore, Article 17 paragraph (1) letter a of the Income Tax Law stipulates that the Income Tax Rate applied on the Assessable Income of the Domestic Individual Taxpayers is as follows. See table 5

Based on the above mentioned regulation, the formula to calculate Income Tax Payable Article 21 in Indonesia is as follows.

Income Tax Article $21=$ Assessable Income $x$ Tax Rate

provided in Table 4 and 5, the Income Tax Article 21 for unmarried work ers with no dependent, who work in those 12 regions, is as follows. See table 6.

\section{Discussion}

From 152 population involved in this research that consist of 27 Provinces and 125 Regency / City, amazingly, only 1 (one) Province and 11 Regency/City in which their Regional Minimum Wages are subject to Income Tax Article 21. Those regions are the Province of Jakarta Special Administrative Region (SAR), Regency of Bekasi, City of Bekas i, City of D epok, Regency of Bogor, City of Bogor, Regency of Karawang, City of Tang erang, Regency of Tangerang, City of South Tangerang, City of Cilegon, and Regency of Serang. In this sense, the workers who work in those regions will get take home pay amount less than the Regional
Minimum Wages set by the Local Government. The following table will show the monthly and annual wages of the workers who work in those region, following by their Income Tax.

The Income Tax paid by the workers in the regions describe in Table 7 to the Central Government through withholding mechanism by their employer, off course will affect the level of their welfare. The problem is how far this Income Tax imposed by the Central Government towards their wages has significant influence and negative impact towards their welfare. For answering this, the figure in Table 7 will present the workers' Gross Income amount in a year along with the percentage of their Income Tax towards the annual Gross Income, following by the percentage of their take home pay amount towards their annual Gross Income. The formula to calculate the take home pay amount is as follows.

Take Home Pay = Gross Income - Income Tax Article 21

According to the above table, the Income Tax is imposed heaviest towards the workers who work in the City of Tangerang with the percentage of Income Tax amounting to $0.51 \%$ (zero point five one percent) from the workers annual Gross Income. The second highest Income Tax burden is i mposed to the workers who work in the Jakarta Special Administra-

Table 6. Workers' Income Tax Article 21 in 2013 (in Rupiah)

\begin{tabular}{|c|c|c|c|c|}
\hline & & $\mathrm{A}$ & $\mathrm{B}$ & $\mathrm{C}$ \\
\hline No & Name of Province / Regency / City & $\begin{array}{l}\text { Assessable } \\
\text { Income }\end{array}$ & $\begin{array}{l}\text { Tax } \\
\text { Rate }\end{array}$ & $\begin{array}{c}\text { Income Tax } \\
\text { Article } 21 \text { in } \\
\text { a Year } \\
=\mathrm{A} \times \mathrm{B}\end{array}$ \\
\hline 1 & Province of Jakarta SAR & $2,870,000$ & $5 \%$ & 143,500 \\
\hline 2 & Regency of Bekasi - West Java & 424,000 & $5 \%$ & 21,200 \\
\hline 3 & City of Bekasi - West Java & $1,635,000$ & $5 \%$ & 81,750 \\
\hline 4 & City of Depok - West Java & 918,000 & $5 \%$ & 45,900 \\
\hline 5 & Regency of Bogor - West Java & 424,000 & $5 \%$ & 21,200 \\
\hline 6 & City of Bogor - West Java & 424,000 & $5 \%$ & 21,200 \\
\hline 7 & Regency of Karawang - West Java & 400,000 & $5 \%$ & 20,000 \\
\hline 8 & City of Tangerang - Banten & $2,907,000$ & $5 \%$ & 145,350 \\
\hline 9 & Regency of Tangerang - Banten & $2,870,000$ & $5 \%$ & 143,500 \\
\hline 10 & City of South Tangerang - Banten & $2,870,000$ & $5 \%$ & 143,500 \\
\hline 11 & City of Cilegon - Banten & $2,870,000$ & $5 \%$ & 143,500 \\
\hline 12 & Regency of Serang - Banten & $1,388,000$ & $5 \%$ & 69,400 \\
\hline
\end{tabular}




\section{Jurnal Ekonomi Pembangunan, 15 (2), Desember 2014, 172-190}

Table 7. Income Tax and Take Home Pay Percentage Towards the Workers' Gross Income in 2013

\begin{tabular}{clccccc}
\hline & & A & \multicolumn{2}{c}{ B } & \multicolumn{2}{c}{$=$ A - B } \\
No & Name of Province / Regency / City & $\begin{array}{c}\text { Annual } \\
\text { Gross } \\
\text { Income } \\
\text { (Rp.) }\end{array}$ & $\begin{array}{c}\text { Annual Income } \\
\text { Tax Article } 21\end{array}$ & \multicolumn{2}{c}{$\begin{array}{c}\text { Annual Take Home } \\
\text { Amount }\end{array}$} \\
& & (Rp.) & $\%$ & (Rp.) & $\%$ \\
\hline 1 & Province of Jakarta SAR & $28,600,000$ & 143,500 & $0.50 \%$ & $28,456,500$ & $99.50 \%$ \\
2 & Regency of Bekasi - West Java & $26,026,000$ & 21,200 & $0.08 \%$ & $26,004,800$ & $99.92 \%$ \\
3 & City of Bekasi - West Java & $27,300,000$ & 81,750 & $0.30 \%$ & $27,218,250$ & $99.70 \%$ \\
4 & City of Depok - West Java & $26,546,000$ & 45,900 & $0.17 \%$ & $26,500,100$ & $99.83 \%$ \\
5 & Regency of Bogor - West Java & $26,026,000$ & 21,200 & $0.08 \%$ & $26,004,800$ & $99.92 \%$ \\
6 & City of Bogor - West Java & $26,026,000$ & 21,200 & $0.08 \%$ & $26,004,800$ & $99.92 \%$ \\
7 & Regency of Karawang - West Java & $26,000,000$ & 20,000 & $0.08 \%$ & $25,980,000$ & $99.92 \%$ \\
8 & City of Tangerang - Banten & $28,639,000$ & 145,350 & $0.51 \%$ & $28,493,650$ & $99.49 \%$ \\
9 & Regency of Tangerang - Banten & $28,600,000$ & 143,500 & $0.50 \%$ & $28,456,500$ & $99.50 \%$ \\
10 & City of South Tangerang - Banten & $28,600,000$ & 143,500 & $0.50 \%$ & $28,456,500$ & $99.50 \%$ \\
11 & City of Cilegon - Banten & $28,600,000$ & 143,500 & $0.50 \%$ & $28,456,500$ & $99.50 \%$ \\
12 & Regency of Serang - Banten & $27,040,000$ & 69,400 & $0.26 \%$ & $26,970,600$ & $99.74 \%$ \\
\hline
\end{tabular}

tive Region (SAR), the Regency of Tangerang, the City of South Tangerang, and the City of Cilegon. In those regions, the percentage of Income Tax imposed by the Central Government is $0.50 \%$ (zero point five percent) from the workers annual Gross Income.

The third highest Income Tax is imposed to the workers who work in the City of Bekasi. In this region, the Income Tax imposed to the workers is $0.30 \%$ (zero point three percent) from their annual Gross Income. The fourth highest Income Tax burden is imposed to the workers who work in the Regency of Serang. The workers who work in this region is imposed by the Income Tax amounting to 0.26 (zero point two six percent) from their annual Gross Income.

The next less burdensome Income Tax is followed by the City of Depok. In this City, the Income Tax imposed to the workers is $0.17 \%$ (zero point one seven percent) from their annual Gross Income. The least burdensome Income Tax is imposed to the workers who work in the Regency of Bekasi, the Regency of Bogor, the City of Bogor, and the Regency of Karawang. The workers who work in those region is imposed by Income Tax amounting to $0.08 \%$ (zero point zero eight percent) from their annual Gross Income.

In general, the Income Tax Article 21 imposed by the Central Government in the national level towards the Regional Minimum Wages of the workers in the regional level is not burdensome. In fact, the percentage of Income Tax to the annual Gross Income of the workers who work in those region are still under the lowest marginal tax rate of Domestic Individual Taxpayers, which in this case is $5 \%$ (five percent). Broadly speaking, the Income Tax imposed to the wages of the workers in those 12 (twelve) regions do not have significant impact towards their welfare because their wages' take home pay amount are still within the range of $99.49 \%$ (ninety nine point four nine percent) to $99.92 \%$ (ninety nine point nine two percent) from their annual Gross Income.

\section{Conclusion}

By referring to the figure in Table 8 , it can be concluded that if the increment of the Regional Minimum Wages set by the Local Government are really based on the Proper Living Standard in each Province, Regency, or City, the increment of the Regional Minimum Wages in the regional level and the increment of the limit of Personal Exemption for Individual Taxpayers in the national level, effective to increase the welfare of the workers in each regions. Encouragement for the next future research, does the wages of the workers in 


\section{Jurnal Ekonomi Pembangunan, 15 (2), Desember 2014, 172-190}

Indonesia are so low that even the Income Tax itself cannot reach or the income brackets in relation to the Income Tax Rate are too high for netting the Income of the workers.

\section{References}

Ambon Ekspres 2012, UMP Maluku 2013 Sebesar Rp 1,275 Juta, Ambon, viewed 1 January 2013,

$<$ http://www.ambonekspres.com/ $\mathrm{n}=$ read\&cat $=40 \& \mathrm{id}=40530>$.

Antaramataram.com 2012, Gubernur Putuskan UMP NTB 2013 Rp 1,1 Juta, Mataram, viewed 1 January 2013, <http://www. antaramataram.

com/berita/index.php?rubrik=5\&id $=2364$ 9>.

Antaranews.com 2012, Gubernur Sulut Tetapkan UMP 2013 Sebesar Rp 1.550 Ribu, Manado, viewed 1 January 2013, <http:// manado.antaranews.com/berita/18023/gu bernur-sulut-tetapkan-ump-2013sebesar-rp1550-ribu>.

Antaranews.com 2012, UMK Makassar Rp 1,5 Juta disepakati Walkot, Makassar, viewed 1 January 2013, <http://www. antaranews.com/berita/343132/umkmakassar-rp15-juta-disepakati-walkot>.

Governor of Aceh Province 2012, Peraturan Gubernur Aceh Nomor 65 Tahun 2012 Tentang Upah Minimum Provinsi (UMP) Aceh, Banda Aceh, viewed 1 January 2013, <http://atjehlink. com/pemerintahdiminta-segera-sosialisasikan-ump-aceh2013/>.

Governor of Bali Province 2012, Peraturan Gubernur Bali Nomor 44 Tahun 2012 Tentang Upah Minimum Kabupaten / Kota, Denpasar, viewed 1 January 2013, $<$ http://www.bursakerjabali.com/ informasi_file/1355186577_umk\%202013. pdf $>$.

Governor of Bangka Belitung Province 2012, Keputusan Gubernur Bangka Belitung Nomor 188.44/792/TK.T/2012 Tentang Penetapan Upah Minimum Kabupaten / Kota (UMK) dan Upah Minimum Sektoral Kabupaten / Kota (UMSK), Pangkal Pinang, viewed 1 January 2013, $<$ http://cetak.bangkapos.com/tbangka/rea $\mathrm{d} / 53235 . \mathrm{html}>$

Governor of Banten Province 2012, Keputusan Gubernur Banten Nomor 561/Kep.904Huk/2012 Tentang Penetapan Upah Minimum Kabupaten / Kota se-Provinsi Banten Tahun 2013, Serang, viewed 1 January 2013, <http://banten. antaranews.com/berita/18242/gubernurbanten-siap-hadapi-gugatan-penetapanumk>.

Governor of Bengkulu Province 2012, Keputusan Gubernur Bengkulu Nomor D.308. XIV. Tahun 2012 Tentang Upah Minimum Provinsi Bengkulu Tahun 2013, Bengkulu, viewed 1 January 2013, $<$ http://harianrakyatbengkulu.com/finalump-rp-12-juta/>.

Governor of Central Java Province 2012, Keputusan Gubernur Jawa Tengah Nomor 561.4/58/2012 Tentang Upah Minimum Pada 35 Kabupaten / Kota di Jawa Tengah, Semarang, viewed 1 January 2013, <http:// ekosupriyantospkep.wordpress.com/2012/ 11/18/daftar-upah-minimum-di-35kabupaten-kota-tahun-2013-propinsijawa-tengah/>.

Governor of East Java Province 2012, Peraturan Gubernur Jawa Timur Nomor 72 Tahun 2012 Tentang Upah Minimum Kabupaten / Kota di Jawa Timur Tahun 2013, Surabaya, viewed 1 January 2013, $<$ http://www.pasuruankab.go.id/mod/dow nload/dokumen/pergub\%20jawa\%20timu r\%20nomor\%2072\%20tahun\%202012.p>.

Governor of East Kalimantan Province 2012, Keputusan Gubernur Kalimantan Timur Nomor 561/K.754/2012 Tentang Penetapan Upah Minimum Provinsi Kalimantan Timur Tahun 2013, Samarinda, viewed 1 January 2013, <http://www. kaltimprov.go.id/kaltim.php?page=detail berita\&id $=9911>$

Governor of Gorontalo Province 2012, Keputusan Gubernur Gorontalo Nomor 433/12 /XI/2012 Tentang Penetapan Upah Minimum Provinsi Gorontalo Tahun 2013, Gorontalo, viewed 1 January 2013, $<$ http://www.gorontaloprov.go.id/tenagakerja/251-ump-gorontalo-2013-sebesar- 


\section{Jurnal Ekonomi Pembangunan, 15 (2), Desember 2014, 172-190}

rp-1-175-000>.

Governor of Jakarta Special Administrative Region 2012, Peraturan Gubernur Provinsi Daerah Khusus Ibukota Jakarta Nomor 189 Tahun 2012 Tentang Upah Minimum Provinsi Tahun 2013, Jakarta, viewed 1 January 2013, http://www. beritpajak.com/Download/SK/Detail/Perg ub_189_2012.pdf>

Governor of North Sumatera Province 2012, Keputusan Gubernur Sumatera Utara Nomor 188.44/647/KPTS/2012 Tentang Upah Minimum Provinsi (UMP) Sumatera Utara Tahun 2013, Medan, viewed 1 January 2013, <http:// sumutcyber.com /?open=view\&newsid=22424>.

Governor of Riau Islands Province 2012, Keputusan Gubernur Kepulauan Riau Nomor 687 Tahun 2012 Tentang Penetapan Upah Minimum Provinsi (UMP) Kepulauan Riau Tahun 2013, Tanjung Pinang, viewed 1 January 2013, <http:// sindikasi.inilah.com/read/detail/1922962/ ump-kepri-rp1365087>.

Governor of Riau Province 2012, Peraturan Gubernur Riau Nomor 58 Tahun 2012 Tentang Upah Minimum Provinsi Tahun 2013 Provinsi Riau, Pekanbaru, viewed 1 January 2013, <http://fokusriau.com/ berita-1967-rusli-zainal-terbitkanpergub-ump-riau-senilai-rp14juta.html>.

Governor of South East Sulawesi Province 2012, Peraturan Gubernur Sulawesi Tenggara Nomor 29 Tahun 2012 Tentang Besaran Nilai Upah Minimum Provinsi Tahun 2013, Kendari, viewed 1 January 2013, <http://rsa991fm.wordpress.com/ 2012/11/17/ump-sultra-2013-naik-9/>.

Governor of South Kalimantan Province 2012, Keputusan Gubernur Kalimantan Selatan Nomor 188.44/0502/Kum/2012 Tentang Penetapan Upah Minimum Provinsi Kalimantan Selatan Tahun 2013, Banjarmasin, viewed 1 January 2013, <http://www.hulusungaitengahkab.go.id/i ndex.php?beritadetail=531\#.UOKuG6zYlxI/>.

Governor of South Sulawesi Province 2012, Keputusan Gubernur Sulawesi Selatan
Nomor 2550/X/2012 Tentang Penetapan Upah Minimum Provinsi Sulawesi Selatan Tahun 2013, Makassar, viewed 1 January 2013, <http://www.sulsel.go.id/ content/pemprov-sahkan-ump-sulsel>.

Governor of South Sumatera Province 2012, Keputusan Gubernur Sumatera Selatan Nomor 745 / KPTS/DISNAKERTRANS / 2012 Tentang Penetapan Upah Minimum Provinsi, Palembang, viewed 1 January 2013, < <ttp://palembang-pos.com/ index.php? option=com_content\&view =article\&id=7699:tolak-upahmurah\&catid=70:plembangkito\&Itemid $=76>$.

Governor of West Java Province 2012, Keputusan Gubernur Jawa Barat Nomor 561/Kep.1405-Bangsos/2012 Tentang Upah Minimum Kabupaten / Kota di Jawa Barat Tahun 2013, Bandung, viewed 1 January 2013, <http:// rumahburuh.com/wp-content/uploads/ 2012/11/SK-Gubernur-UMK-2013.pdf>.

Governor of West Kalimantan Province 2012, Keputusan Gubernur Kalimantan Barat Nomor 632/KESSOS/2012 Tentang Penetapan Upah Minimum Kota Pontianak Tahun 2013, Pontianak, viewed 1 January 2013, <http://www. pontianakkota.go.id/?q=news/umk-rp1165000-berlaku-mulai-2013>.

Governor of West Sumatera Province 2012, Keputusan Gubernur Sumatera Barat Nomor 562-781-2012 Tentang Penetapan Upah Minimum Provinsi (UMP) Sumatera Barat, Padang, viewed 1 January 2013, <http://www. padangmedia.com/1-Berit a/77377-PengusahaDilarang-Turunkan-Upah-DiatasUMP.html>.

Governor of Yogyakarta Special Administrative Region 2012, Keputusan Gubernur Daerah Istimewa Yogyakarta Nomor 370/KEP/2012 Tentang Upah Minimum Kabupaten / Kota Tahun 2013 di Daerah Istimewa Yogyakarta, Yogyakarta, viewed 1 January 2013, <http://www. nakertrans.jogjaprov.go.id/contentdetil.p $\mathrm{hp}$ ?kat=brta\&id=NTk=\&fle=aW5kZXguc Ghw\&lback=>. 
Harian Pagi Timor Express Kupang 2012, 2013, UMP NTT Rp 1.010.000, Kupang, viewed 1 January 2013 , $<$ http://www.timorexpress.com/index.php ?act=news\&nid $=52387>$.

Harian Rakyat Kalbar The New Equator 2012, KSBSI: UMP Kalbar Rendah, Pontianak, viewed 1 January 2013, <http://www. equator-news.com/utama/20121126/ ksbsi-ump-kalbar-rendah>.

Jambiekspres News 2012, 2013, UMR Rp 1,3 Juta, Sengeti, viewed 1 January 2013, $<$ http://www.jambiekspres.co.id/berita2356-2013-umr-rp-13-juta.html>.

JProperty 2012, Penetapan UMP 2013 di Lampung, Bandar Lampung, viewed 1 January 2013, <http://jproperty.org/ump2013.html>.

Kompas.com 2012, UMP Papua 2013 Rp 1,71 Juta, Biak, viewed 1 January 2013, $<$ http://megapolitan.kompas.com/read/20 12/11/17/10384515/UMP.Papua.2013.Rp. 1.71.Juta>.

Malutpost.co.id 2012, UMP Malut Disepakati $R p$ 1,1 Juta, Sofifi, viewed 1 January 2013, <http://malutpost.co.id/?p=6061>.

Radar-Sulbar.com 2012, Dewan Pengupahan Telat Laporkan UMP 2012 Sulbar, Mamuju, viewed 1 January 2013, $<$ http://www.radar-sulbar.com/ mamuju/dewan-pengupahan-telatlaporkan-ump-2012-sulbar-2/>.

Radar Sulteng 2012, UMP Sulteng Sudah Diteken, Palu, viewed 1 January 2013, $<$ http://www.radarsulteng.co.id/index.php /berita/detail/Rubrik/42/6008>.

Sindonews.com 2012, 17 Provinsi Telah Tetapkan UMP 2013, Jakarta, viewed 1 January 2013, <http://ekbis.sindonews. com/read/2012/11/21/34/690283/17provinsi-telah-tetapkan-ump-2013>.

The Government of the Republic of Indonesia 2008, Undang-Undang Nomor 7 Tahun 1983 Tentang Pajak Penghasilan sebagaimana telah diubah terakhir dengan Undang-Undang Nomor 36 Tahun 2008, Jakarta, viewed 1 January $2013,<$ http://www.pajak.go.id/ dmdocuments/UU-36-2008.pdf $>$.

The Local Government of Manokwari Regency 2012, UMP Papua Barat Rp 1.720.000, Manokwari, viewed 1 January 2013, $<$ http://www.manokwarikab.go.id/website -kabupaten-manokwari-wwwmanokwarikabgoid/news206821886 6/78-latest-news1958260390-latestnews1958260390/1731-ump-papua-baratrp-1720000>.

The Ministry of Finance of the Republic of Indonesia 2008, Peraturan Menteri Keuangan Nomor 250/PMK.03/2008 Tentang Besarnya Biaya Jabatan atau Biaya Pensiun yang dapat dikurangkan dari Penghasilan Bruto Pegawai Tetap atau Pensiunan, Jakarta, viewed 1 January 2013, <http://triyani.files. wordpress.com/ 2009/01/pmk250mk032008biayajabatan.pdf $>$.

The Ministry of Finance of the Republic of Indonesia 2012, Peraturan Menteri Keuangan Nomor 162/PMK.011/2011 Tentang Penyesuaian Besarnya Penghasilan Tidak Kena Pajak, Jakarta, viewed 1 January 2013, <http://triyani.files. wordpress.com/2012/11/pmk162_2012ptkp.pdf>. 
Jurnal Ekonomi Pembangunan, 15 (2), Desember 2014, 172-190

\section{Lampiran}

Table 1. List of Regional Minimum Wages in 2013

\begin{tabular}{|c|c|c|c|}
\hline No & Name of Province / Regency / City & Monthly Wages (Rp.) & Level \\
\hline 1 & Province of Nanggroe Aceh Darussalam & $1,550,000$ & Province \\
\hline 2 & Province of North Sumatera & $1,305,000$ & Province \\
\hline 3 & Province of West Sumatera & $1,350,000$ & Province \\
\hline 4 & Province of Riau & $1,400,000$ & Province \\
\hline 5 & Province of Riau Islands & $1,365,087$ & Province \\
\hline 6 & Province of Jambi & $1,300,000$ & Province \\
\hline 7 & Province of South Sumatera & $1,350,000$ & Province \\
\hline 8 & Province of Bangka - Belitung & $1,622,400$ & Province \\
\hline 9 & Province of Bengkulu & $1,200,000$ & Province \\
\hline 10 & Province of Lampung & $1,150,000$ & Province \\
\hline 11 & Province of Jakarta Special Administrative Region & $2,200,000$ & Province \\
\hline 12 & Province of West Nusa Tenggara & $1,100,000$ & Province \\
\hline 13 & Province of East Nusa Tenggara & $1,010,000$ & Province \\
\hline 14 & Province of West Kalimantan & $1,060,000$ & Province \\
\hline 15 & Province of South Kalimantan & $1,337,500$ & Province \\
\hline 16 & Province of Central Kalimantan & $1,553,127$ & Province \\
\hline 17 & Province of East Kalimantan & $1,752,000$ & Province \\
\hline 18 & Province of Maluku & $1,275,000$ & Province \\
\hline 19 & Province of North Maluku & $1,152,598$ & Province \\
\hline 20 & Province of Gorontalo & $1,175,000$ & Province \\
\hline 21 & Province of North Sulawesi & $1,550,000$ & Province \\
\hline 22 & Province of South East Sulawesi & $1,125,000$ & Province \\
\hline 23 & Province of Central Sulawesi & 995,000 & Province \\
\hline 24 & Province of South Sulawesi & $1,440,000$ & Province \\
\hline 25 & Province of West Sulawesi & $1,127,000$ & Province \\
\hline 26 & Province of Papua & $1,710,000$ & Province \\
\hline 27 & Province of West Papua & $1,720,000$ & Province \\
\hline 28 & Regency of Tasikmalaya - West Java & $1,035,000$ & Regency \\
\hline 29 & Regency of Ciamis - West Java & 854,075 & Regency \\
\hline 30 & City of Sukabumi - West Java & $1,050,000$ & City \\
\hline 31 & Regency of Garut - West Java & 965,000 & Regency \\
\hline 32 & City of Banjar - West Java & 950,000 & City \\
\hline 33 & Regency of Majalengka - West Java & 850,000 & Regency \\
\hline 34 & Regency of Sukabumi - West Java & $1,201,020$ & Regency \\
\hline 35 & Regency of Cirebon - West Java & $1,081,300$ & Regency \\
\hline 36 & Regency of Bandung - West Java & $1,388,333$ & Regency \\
\hline 37 & Regency of Sumedang - West Java & $1,381,700$ & Regency \\
\hline 38 & City of Tasikmalaya - West Java & $1,045,000$ & City \\
\hline 39 & Regency of Kuningan - West Java & 857,000 & Regency \\
\hline 40 & City of Cirebon - West Java & $1,082,500$ & City \\
\hline 41 & Regency of Cianjur - West Java & 970,000 & Regency \\
\hline 42 & City of Bandung - West Java & $1,538,703$ & City \\
\hline 43 & Regency of Subang - West Java & $1,220,000$ & Regency \\
\hline 44 & Regency of Bekasi - West Java & $2,002,000$ & Regency \\
\hline 45 & Regency of Indramayu - West Java & $1,125,000$ & Regency \\
\hline 46 & City of Cimahi - West Java & $1,388,333$ & City \\
\hline 47 & City of Bekasi - West Java & $2,100,000$ & City \\
\hline 48 & Regency of Purwakarta - West Java & $1,693,167$ & Regency \\
\hline 49 & Regency of Bandung Barat - West Java & $1,396,399$ & Regency \\
\hline 50 & City of Depok - West Java & $2,042,000$ & City \\
\hline 51 & Regency of Bogor - West Java & $2,002,000$ & Regency \\
\hline 52 & City of Bogor - West Java & $2,002,000$ & City \\
\hline 53 & Regency of Karawang - West Java & $2,000,000$ & Regency \\
\hline
\end{tabular}


Jurnal Ekonomi Pembangunan, 15 (2), Desember 2014, 172-190

\begin{tabular}{|c|c|c|c|}
\hline No & Name of Province / Regency / City & Monthly Wages (Rp.) & Level \\
\hline 54 & Regency of Lebak - Banten & $1,187,500$ & Regency \\
\hline 55 & City of Serang - Banten & $1,798,446$ & City \\
\hline 56 & Regency of Pandeglang - Banten & $1,182,000$ & Regency \\
\hline 57 & City of Tangerang - Banten & $2,203,000$ & City \\
\hline 58 & Regency of Tangerang - Banten & $2,200,000$ & Regency \\
\hline 59 & City of South Tangerang - Banten & $2,200,000$ & City \\
\hline 60 & City of Cilegon - Banten & $2,200,000$ & City \\
\hline 61 & Regency of Serang - Banten & $2,080,000$ & Regency \\
\hline 62 & City of Semarang - Central Java & $1,209,100$ & City \\
\hline 63 & Regency of Demak - Central Java & 995,000 & Regency \\
\hline 64 & Regency of Kendal - Central Java & 953,000 & Regency \\
\hline 65 & Regency of Semarang - Central Java & $1,051,000$ & Regency \\
\hline 66 & City of Salatiga - Central Java & 974,000 & City \\
\hline 67 & Regency of Grobogan - Central Java & 842,000 & Regency \\
\hline 68 & Regency of Blora - Central Java & 932,000 & Regency \\
\hline 69 & Regency of Kudus - Central Java & 990,000 & Regency \\
\hline 70 & Regency of Jepara - Central Java & 875,000 & Regency \\
\hline 71 & Regency of Pati - Central Java & 927,600 & Regency \\
\hline 72 & Regency of Rembang - Central Java & 896,000 & Regency \\
\hline 73 & Regency of Boyolali - Central Java & 895,000 & Regency \\
\hline 74 & City of Surakarta - Central Java & 915,900 & City \\
\hline 75 & Regency of Sukoharjo - Central Java & 902,000 & Regency \\
\hline 76 & Regency of Sragen - Central Java & 864,000 & Regency \\
\hline 77 & Regency of Karanganyar - Central Java & 896,500 & Regency \\
\hline 78 & Regency of Wonogiri - Central Java & 830,000 & Regency \\
\hline 79 & Regency of Klaten - Central Java & 871,500 & Regency \\
\hline 80 & City of Magelang - Central Java & 901,500 & City \\
\hline 81 & Regency of Magelang - Central Java & 942,000 & Regency \\
\hline 82 & Regency of Purworejo - Central Java & 849,000 & Regency \\
\hline 83 & Regency of Temanggung - Central Java & 940,000 & Regency \\
\hline 84 & Regency of Wonosobo - Central Java & 880,000 & Regency \\
\hline 85 & Regency of Kebumen - Central Java & 835,000 & Regency \\
\hline 86 & Regency of Banyumas - Central Java & 877,500 & Regency \\
\hline 87 & Regency of Cilacap City - Central Java & 986,000 & Regency \\
\hline 88 & Regency of East Cilacap - Central Java & 861,000 & Regency \\
\hline 89 & Regency of West Cilacap - Central Java & 816,000 & Regency \\
\hline 90 & Regency of Banjarnegara - Central Java & 835,000 & Regency \\
\hline 91 & Regency of Purbalingga - Central Java & 896,500 & Regency \\
\hline 92 & Regency of Batang - Central Java & 970,000 & Regency \\
\hline 93 & City of Pekalongan - Central Java & 980,000 & City \\
\hline 94 & Regency of Pekalongan - Central Java & 962,000 & Regency \\
\hline 95 & Regency of Pemalang - Central Java & 908,000 & Regency \\
\hline 96 & City of Tegal - Central Java & 860,000 & City \\
\hline 97 & Regency of Tegal - Central Java & 860,000 & Regency \\
\hline 98 & Regency of Brebes - Central Java & 859,000 & Regency \\
\hline 99 & City of Yogyakarta - Yogyakarta SAR & $1,065,247$ & City \\
\hline 100 & Regency of Sleman - Yogyakarta SAR & $1,026,181$ & Regency \\
\hline 101 & Regency of Bantul - Yogyakarta SAR & 993,484 & Regency \\
\hline 102 & Regency of Kulon Progo - Yogyakarta SAR & 954,339 & Regency \\
\hline 103 & Regency of Gunung Kidul - Yogyakarta SAR & 947,114 & Regency \\
\hline 104 & City of Surabaya - East Java & $1,740,000$ & City \\
\hline 105 & Regency of Gresik - East Java & $1,740,000$ & Regency \\
\hline 106 & Regency of Pasuruan - East Java & $1,720,000$ & Regency \\
\hline 107 & Regency of Sidoarjo - East Java & $1,720,000$ & Regency \\
\hline 108 & Regency of Mojokerto - East Java & $1,700,000$ & Regency \\
\hline 109 & Regency of Malang - East Java & $1,343,700$ & Regency \\
\hline 110 & City of Malang - East Java & $1,340,300$ & City \\
\hline 111 & City of Batu - East Java & $1,268,000$ & City \\
\hline
\end{tabular}


Jurnal Ekonomi Pembangunan, 15 (2), Desember 2014, 172-190

\begin{tabular}{|c|c|c|c|}
\hline No & Name of Province / Regency / City & Monthly Wages (Rp.) & Level \\
\hline 112 & Regency of Jombang - East Java & $1,200,000$ & Regency \\
\hline 113 & Regency of Probolinggo - East Java & $1,198,600$ & Regency \\
\hline 114 & City of Pasuruan - East Java & $1,195,800$ & City \\
\hline 115 & Regency of Tuban - East Java & $1,144,400$ & Regency \\
\hline 116 & City of Kediri - East Java & $1,128,400$ & City \\
\hline 117 & Regency of Sampang - East Java & $1,104,600$ & Regency \\
\hline 118 & City of Probolinggo - East Java & $1,103,200$ & City \\
\hline 119 & Regency of Jember - East Java & $1,091,950$ & Regency \\
\hline 120 & Regency of Kediri - East Java & $1,089,950$ & Regency \\
\hline 121 & Regency of Banyuwangi - East Java & $1,086,400$ & Regency \\
\hline 122 & Regency of Lamongan - East Java & $1,075,700$ & Regency \\
\hline 123 & Regency of Pamekasan - East Java & $1,059,600$ & Regency \\
\hline 124 & Regency of Situbondo - East Java & $1,048,000$ & Regency \\
\hline 125 & City of Mojokerto - East Java & $1,040,000$ & City \\
\hline 126 & Regency of Bojonegoro - East Java & $1,029,500$ & Regency \\
\hline 127 & Regency of Lumajang - East Java & $1,011,950$ & Regency \\
\hline 128 & Regency of Tulungagung - East Java & $1,007,900$ & Regency \\
\hline 129 & Regency of Bangkalan - East Java & 983,800 & Regency \\
\hline 130 & Regency of Sumenep - East Java & 965,000 & Regency \\
\hline 131 & Regency of Madiun - East Java & 960,750 & Regency \\
\hline 132 & Regency of Nganjuk - East Java & 960,200 & Regency \\
\hline 133 & City of Madiun - East Java & 953,000 & City \\
\hline 134 & Regency of Blitar - East Java & 946,850 & Regency \\
\hline 135 & Regency of Bondowoso - East Java & 946,000 & Regency \\
\hline 136 & City of Blitar - East Java & 924,800 & City \\
\hline 137 & Regency of Ponorogo - East Java & 924,000 & Regency \\
\hline 138 & Regency of Trenggalek - East Java & 903,900 & Regency \\
\hline 139 & Regency of Ngawi - East Java & 900,000 & Regency \\
\hline 140 & Regency of Pacitan - East Java & 887,250 & Regency \\
\hline 141 & Regency of Magetan - East Java & 866,250 & Regency \\
\hline 142 & Regency of Badung - Bali & $1,401,000$ & Regency \\
\hline 143 & City of Denpasar - Bali & $1,358,000$ & City \\
\hline 144 & Regency of Gianyar - Bali & $1,230,000$ & Regency \\
\hline 145 & Regency of Karangasem - Bali & $1,195,000$ & Regency \\
\hline 146 & Regency of Jembrana - Bali & $1,212,500$ & Regency \\
\hline 147 & Regency of Tabanan - Bali & $1,250,000$ & Regency \\
\hline 148 & Regency of Klungkung - Bali & $1,190,000$ & Regency \\
\hline 149 & Regency of Buleleng - Bali & $1,200,000$ & Regency \\
\hline 150 & Regency of Bangli - Bali & $1,182,000$ & Regency \\
\hline 151 & City of Pontianak - West Kalimantan & $1,165,000$ & City \\
\hline 152 & City of Makassar - South Sulawesi & $1,500,000$ & City \\
\hline
\end{tabular}

Table 2. Workers' Annual Gross Income in 2013

\begin{tabular}{|c|c|c|c|}
\hline & & $\mathrm{A}$ & $\mathrm{B}$ \\
\hline No & Name of Province / Regency / City & $\begin{array}{c}\text { Monthly } \\
\text { Wages (Rp.) }\end{array}$ & $\begin{array}{l}\text { Annual Gross } \\
\text { Income (Rp.) } \\
=\mathrm{A} \times 13\end{array}$ \\
\hline 1 & Province of Nanggroe Aceh Darussalam & $1,550,000$ & $20,150,000$ \\
\hline 2 & Province of North Sumatera & $1,305,000$ & $16,965,000$ \\
\hline 3 & Province of West Sumatera & $1,350,000$ & $17,550,000$ \\
\hline 4 & Province of Riau & $1,400,000$ & $18,200,000$ \\
\hline 5 & Province of Riau Islands & $1,365,087$ & $17,746,131$ \\
\hline 6 & Province of Jambi & $1,300,000$ & $16,900,000$ \\
\hline 7 & Province of South Sumatera & $1,350,000$ & $17,550,000$ \\
\hline 8 & Province of Bangka - Belitung & $1,622,400$ & $19,468,800$ \\
\hline
\end{tabular}




\begin{tabular}{|c|c|c|c|}
\hline & & A & $\mathrm{B}$ \\
\hline No & Name of Province / Regency / City & $\begin{array}{c}\text { Monthly } \\
\text { Wages (Rp.) }\end{array}$ & $\begin{array}{c}\text { Annual Gross } \\
\text { Income (Rp.) } \\
=\mathrm{A} \times 13\end{array}$ \\
\hline 9 & Province of Bengkulu & $1,200,000$ & $15,600,000$ \\
\hline 10 & Province of Lampung & $1,150,000$ & $14,950,000$ \\
\hline 11 & Province of Jakarta Special Administrative Region & $2,200,000$ & $28,600,000$ \\
\hline 12 & Province of West Nusa Tenggara & $1,100,000$ & $14,300,000$ \\
\hline 13 & Province of East Nusa Tenggara & $1,010,000$ & $13,130,000$ \\
\hline 14 & Province of West Kalimantan & $1,060,000$ & $13,780,000$ \\
\hline 15 & Province of South Kalimantan & $1,337,500$ & $17,387,500$ \\
\hline 16 & Province of Central Kalimantan & $1,553,127$ & $20,190,651$ \\
\hline 17 & Province of East Kalimantan & $1,752,000$ & $21,024,000$ \\
\hline 18 & Province of Maluku & $1,275,000$ & $16,575,000$ \\
\hline 19 & Province of North Maluku & $1,152,598$ & $14,983,774$ \\
\hline 20 & Province of Gorontalo & $1,175,000$ & $15,275,000$ \\
\hline 21 & Province of North Sulawesi & $1,550,000$ & $20,150,000$ \\
\hline 22 & Province of South East Sulawesi & $1,125,000$ & $13,500,000$ \\
\hline 23 & Province of Central Sulawesi & 995,000 & $12,935,000$ \\
\hline 24 & Province of South Sulawesi & $1,440,000$ & $18,720,000$ \\
\hline 25 & Province of West Sulawesi & $1,127,000$ & $13,524,000$ \\
\hline 26 & Province of Papua & $1,710,000$ & $22,230,000$ \\
\hline 27 & Province of West Papua & $1,720,000$ & $22,360,000$ \\
\hline 28 & Regency of Tasikmalaya - West Java & $1,035,000$ & $13,455,000$ \\
\hline 29 & Regency of Ciamis - West Java & 854,075 & $11,102,975$ \\
\hline 30 & City of Sukabumi - West Java & $1,050,000$ & $13,650,000$ \\
\hline 31 & Regency of Garut - West Java & 965,000 & $12,545,000$ \\
\hline 32 & City of Banjar - West Java & 950,000 & $12,350,000$ \\
\hline 33 & Regency of Majalengka - West Java & 850,000 & $11,050,000$ \\
\hline 34 & Regency of Sukabumi - West Java & $1,201,020$ & $15,613,260$ \\
\hline 35 & Regency of Cirebon - West Java & $1,081,300$ & $14,056,900$ \\
\hline 36 & Regency of Bandung - West Java & $1,388,333$ & $18,048,329$ \\
\hline 37 & Regency of Sumedang - West Java & $1,381,700$ & $17,962,100$ \\
\hline 38 & City of Tasikmalaya - West Java & $1,045,000$ & $13,585,000$ \\
\hline 39 & Regency of Kuningan - West Java & 857,000 & $11,141,000$ \\
\hline 40 & City of Cirebon - West Java & $1,082,500$ & $14,072,500$ \\
\hline 41 & Regency of Cianjur - West Java & 970,000 & $12,610,000$ \\
\hline 42 & City of Bandung - West Java & $1,538,703$ & $20,003,139$ \\
\hline 43 & Regency of Subang - West Java & $1,220,000$ & $15,860,000$ \\
\hline 44 & Regency of Bekasi - West Java & $2,002,000$ & $26,026,000$ \\
\hline 45 & Regency of Indramayu - West Java & $1,125,000$ & $14,625,000$ \\
\hline 46 & City of Cimahi - West Java & $1,388,333$ & $18,048,329$ \\
\hline 47 & City of Bekasi - West Java & $2,100,000$ & $27,300,000$ \\
\hline 48 & Regency of Purwakarta - West Java & $1,693,167$ & $22,011,171$ \\
\hline 49 & Regency of Bandung Barat - West Java & $1,396,399$ & $18,153,187$ \\
\hline 50 & City of Depok - West Java & $2,042,000$ & $26,546,000$ \\
\hline 51 & Regency of Bogor - West Java & $2,002,000$ & $26,026,000$ \\
\hline 52 & City of Bogor - West Java & $2,002,000$ & $26,026,000$ \\
\hline 53 & Regency of Karawang - West Java & $2,000,000$ & $26,000,000$ \\
\hline 54 & Regency of Lebak - Banten & $1,187,500$ & $15,437,500$ \\
\hline 55 & City of Serang - Banten & $1,798,446$ & $23,379,798$ \\
\hline 56 & Regency of Pandeglang - Banten & $1,182,000$ & $15,366,000$ \\
\hline 57 & City of Tangerang - Banten & $2,203,000$ & $28,639,000$ \\
\hline 58 & Regency of Tangerang - Banten & $2,200,000$ & $28,600,000$ \\
\hline 59 & City of South Tangerang - Banten & $2,200,000$ & $28,600,000$ \\
\hline 60 & City of Cilegon - Banten & $2,200,000$ & $28,600,000$ \\
\hline 61 & Regency of Serang - Banten & $2,080,000$ & $27,040,000$ \\
\hline 62 & City of Semarang - Central Java & $1,209,100$ & $15,718,300$ \\
\hline 63 & Regency of Demak - Central Java & 995,000 & $12,935,000$ \\
\hline
\end{tabular}


Jurnal Ekonomi Pembangunan, 15 (2), Desember 2014, 172-190

\begin{tabular}{|c|c|c|c|}
\hline \multirow[b]{2}{*}{ No } & \multirow[b]{2}{*}{ Name of Province / Regency / City } & $\mathrm{A}$ & $\mathrm{B}$ \\
\hline & & $\begin{array}{c}\text { Monthly } \\
\text { Wages (Rp.) }\end{array}$ & $\begin{array}{c}\text { Annual Gross } \\
\text { Income (Rp.) } \\
=\mathrm{A} \times 13\end{array}$ \\
\hline 64 & Regency of Kendal - Central Java & 953,000 & $12,389,000$ \\
\hline 65 & Regency of Semarang - Central Java & $1,051,000$ & $13,663,000$ \\
\hline 66 & City of Salatiga - Central Java & 974,000 & $12,662,000$ \\
\hline 67 & Regency of Grobogan - Central Java & 842,000 & $10,946,000$ \\
\hline 68 & Regency of Blora - Central Java & 932,000 & $12,116,000$ \\
\hline 69 & Regency of Kudus - Central Java & 990,000 & $12,870,000$ \\
\hline 70 & Regency of Jepara - Central Java & 875,000 & $11,375,000$ \\
\hline 71 & Regency of Pati - Central Java & 927,600 & $12,058,800$ \\
\hline 72 & Regency of Rembang - Central Java & 896,000 & $11,648,000$ \\
\hline 73 & Regency of Boyolali - Central Java & 895,000 & $11,635,000$ \\
\hline 74 & City of Surakarta - Central Java & 915,900 & $11,906,700$ \\
\hline 75 & Regency of Sukoharjo - Central Java & 902,000 & $11,726,000$ \\
\hline 76 & Regency of Sragen - Central Java & 864,000 & $11,232,000$ \\
\hline 77 & Regency of Karanganyar - Central Java & 896,500 & $11,654,500$ \\
\hline 78 & Regency of Wonogiri - Central Java & 830,000 & $10,790,000$ \\
\hline 79 & Regency of Klaten - Central Java & 871,500 & $11,329,500$ \\
\hline 80 & City of Magelang - Central Java & 901,500 & $11,719,500$ \\
\hline 81 & Regency of Magelang - Central Java & 942,000 & $12,246,000$ \\
\hline 82 & Regency of Purworejo - Central Java & 849,000 & $11,037,000$ \\
\hline 83 & Regency ofTemanggung - Central Java & 940,000 & $12,220,000$ \\
\hline 84 & Regency of Wonosobo - Central Java & 880,000 & $11,440,000$ \\
\hline 85 & Regency of Kebumen - Central Java & 835,000 & $10,855,000$ \\
\hline 86 & Regency of Banyumas - Central Java & 877,500 & $11,407,500$ \\
\hline 87 & Regency of Cilacap City - Central Java & 986,000 & $12,818,000$ \\
\hline 88 & Regency of East Cilacap - Central Java & 861,000 & $11,193,000$ \\
\hline 89 & Regency of West Cilacap - Central Java & 816,000 & $10,608,000$ \\
\hline 90 & Regency of Banjarnegara - Central Java & 835,000 & $10,855,000$ \\
\hline 91 & Regency of Purbalingga - Central Java & 896,500 & $11,654,500$ \\
\hline 92 & Regency of Batang - Central Java & 970,000 & $12,610,000$ \\
\hline 93 & City of Pekalongan - Central Java & 980,000 & $12,740,000$ \\
\hline 94 & Regency of Pekalongan - Central Java & 962,000 & $12,506,000$ \\
\hline 95 & Regency of Pemalang - Central Java & 908,000 & $11,804,000$ \\
\hline 96 & City of Tegal - Central Java & 860,000 & $11,180,000$ \\
\hline 97 & Regency of Tegal - Central Java & 860,000 & $11,180,000$ \\
\hline 98 & Regency of Brebes - Central Java & 859,000 & $11,167,000$ \\
\hline 99 & City of Yogyakarta - Yogyakarta SAR & $1,065,247$ & $13,848,211$ \\
\hline 100 & Regency of Sleman - Yogyakarta SAR & $1,026,181$ & $13,340,353$ \\
\hline 101 & Regency of Bantul - Yogyakarta SAR & 993,484 & $12,915,292$ \\
\hline 102 & Regency of Kulon Progo - Yogyakarta SAR & 954,339 & $12,406,407$ \\
\hline 103 & Regency of Gunung Kidul - Yogyakarta SAR & 947,114 & $12,312,482$ \\
\hline 104 & City of Surabaya - East Java & $1,740,000$ & $22,620,000$ \\
\hline 105 & Regency of Gresik - East Java & $1,740,000$ & $22,620,000$ \\
\hline 106 & Regency of Pasuruan - East Java & $1,720,000$ & $22,360,000$ \\
\hline 107 & Regency of Sidoarjo - East Java & $1,720,000$ & $22,360,000$ \\
\hline 108 & Regency of Mojokerto - East Java & $1,700,000$ & $22,100,000$ \\
\hline 109 & Regency of Malang - East Java & $1,343,700$ & $17,468,100$ \\
\hline 110 & City of Malang - East Java & $1,340,300$ & $17,423,900$ \\
\hline 111 & City of Batu - East Java & $1,268,000$ & $16,484,000$ \\
\hline 112 & Regency of Jombang - East Java & $1,200,000$ & $15,600,000$ \\
\hline 113 & Regency of Probolinggo - East Java & $1,198,600$ & $15,581,800$ \\
\hline 114 & City of Pasuruan - East Java & $1,195,800$ & $15,545,400$ \\
\hline 115 & Regency of Tuban - East Java & $1,144,400$ & $14,877,200$ \\
\hline 116 & City of Kediri - East Java & $1,128,400$ & $14,669,200$ \\
\hline 117 & Regency of Sampang - East Java & $1,104,600$ & $14,359,800$ \\
\hline 118 & City of Probolinggo - East Java & $1,103,200$ & $14,341,600$ \\
\hline
\end{tabular}


Jurnal Ekonomi Pembangunan, 15 (2), Desember 2014, 172-190

\begin{tabular}{|c|c|c|c|}
\hline & & $\mathrm{A}$ & $\mathrm{B}$ \\
\hline No & Name of Province / Regency / City & $\begin{array}{c}\text { Monthly } \\
\text { Wages (Rp.) }\end{array}$ & $\begin{array}{c}\text { Annual Gross } \\
\text { Income (Rp.) } \\
=\mathrm{A} \text { x } 13\end{array}$ \\
\hline 119 & Regency of Jember - East Java & $1,091,950$ & $14,195,350$ \\
\hline 120 & Regency of Kediri - East Java & $1,089,950$ & $14,169,350$ \\
\hline 121 & Regency of Banyuwangi - East Java & $1,086,400$ & $14,123,200$ \\
\hline 122 & Regency of Lamongan - East Java & $1,075,700$ & $13,984,100$ \\
\hline 123 & Regency of Pamekasan - East Java & $1,059,600$ & $13,774,800$ \\
\hline 124 & Regency of Situbondo - East Java & $1,048,000$ & $13,624,000$ \\
\hline 125 & City of Mojokerto - East Java & $1,040,000$ & $13,520,000$ \\
\hline 126 & Regency of Bojonegoro - East Java & $1,029,500$ & $13,383,500$ \\
\hline 127 & Regency of Lumajang - East Java & $1,011,950$ & $13,155,350$ \\
\hline 128 & Regency of Tulungagung - East Java & $1,007,900$ & $13,102,700$ \\
\hline 129 & Regency of Bangkalan - East Java & 983,800 & $12,789,400$ \\
\hline 130 & Regency of Sumenep - East Java & 965,000 & $12,545,000$ \\
\hline 131 & Regency of Madiun - East Java & 960,750 & $12,489,750$ \\
\hline 132 & Regency of Nganjuk - East Java & 960,200 & $12,482,600$ \\
\hline 133 & City of Madiun - East Java & 953,000 & $12,389,000$ \\
\hline 134 & Regency of Blitar - East Java & 946,850 & $12,309,050$ \\
\hline 135 & Regency of Bondowoso - East Java & 946,000 & $12,298,000$ \\
\hline 136 & City of Blitar - East Java & 924,800 & $12,022,400$ \\
\hline 137 & Regency of Ponorogo - East Java & 924,000 & $12,012,000$ \\
\hline 138 & Regency of Trenggalek - East Java & 903,900 & $11,750,700$ \\
\hline 139 & Regency of Ngawi - East Java & 900,000 & $11,700,000$ \\
\hline 140 & Regency of Pacitan - East Java & 887,250 & $11,534,250$ \\
\hline 141 & Regency of Magetan - East Java & 866,250 & $11,261,250$ \\
\hline 142 & Regency of Badung - Bali & $1,401,000$ & $18,213,000$ \\
\hline 143 & City of Denpasar - Bali & $1,358,000$ & $17,654,000$ \\
\hline 144 & Regency of Gianyar - Bali & $1,230,000$ & $15,990,000$ \\
\hline 145 & Regency of Karangasem - Bali & $1,195,000$ & $15,535,000$ \\
\hline 146 & Regency of Jembrana - Bali & $1,212,500$ & $15,762,500$ \\
\hline 147 & Regency of Tabanan - Bali & $1,250,000$ & $16,250,000$ \\
\hline 148 & Regency of Klungkung - Bali & $1,190,000$ & $15,470,000$ \\
\hline 149 & Regency of Buleleng - Bali & $1,200,000$ & $15,600,000$ \\
\hline 150 & Regency of Bangli - Bali & $1,182,000$ & $15,366,000$ \\
\hline 151 & City of Pontianak - West Kalimantan & $1,165,000$ & $13,980,000$ \\
\hline 152 & City of Makassar - South Sulawesi & $1,500,000$ & $19,500,000$ \\
\hline
\end{tabular}

Table 4. Workers' Assessable Income in 2013 (in Rupiah)

\begin{tabular}{|c|c|c|c|c|c|c|}
\hline & & $\mathrm{A}$ & $\mathrm{B}$ & $\mathrm{C}$ & $\mathrm{D}$ & $\mathrm{E}$ \\
\hline No & $\begin{array}{c}\text { Name of Province / Regency / } \\
\text { City }\end{array}$ & $\begin{array}{l}\text { Gross } \\
\text { Income }\end{array}$ & $\begin{array}{c}\text { Official } \\
\text { Expenditure } \\
=\mathrm{A} \times 5 \%\end{array}$ & $\begin{array}{l}\text { Net Income } \\
\quad=\mathrm{A}-\mathrm{B}\end{array}$ & $\begin{array}{l}\text { Personal } \\
\text { Exemption }\end{array}$ & $\begin{array}{l}\text { Assessable } \\
\text { Income } \\
\text { = C - D }\end{array}$ \\
\hline 1 & $\begin{array}{l}\text { Province of Nanggroe Aceh } \\
\text { Darussalam }\end{array}$ & $20,150,000$ & $1,007,500$ & $19,142,500$ & $24,300,000$ & 0 \\
\hline 2 & Province of North Sumatera & $16,965,000$ & 848,250 & $16,116,750$ & $24,300,000$ & 0 \\
\hline 3 & Province of West Sumatera & $17,550,000$ & 877,500 & $16,672,500$ & $24,300,000$ & 0 \\
\hline 4 & Province of Riau & $18,200,000$ & 910,000 & $17,290,000$ & $24,300,000$ & 0 \\
\hline 5 & Province of Riau Islands & $17,746,131$ & 887,307 & $16,858,824$ & $24,300,000$ & 0 \\
\hline 6 & Province of Jambi & $16,900,000$ & 845,000 & $16,055,000$ & $24,300,000$ & 0 \\
\hline 7 & Province of South Sumatera & $17,550,000$ & 877,500 & $16,672,500$ & $24,300,000$ & 0 \\
\hline 8 & Province of Bangka - Belitung & $21,091,200$ & $1,054,560$ & $20,036,640$ & $24,300,000$ & 0 \\
\hline 9 & Province of Bengkulu & $15,600,000$ & 780,000 & $14,820,000$ & $24,300,000$ & 0 \\
\hline 10 & Province of Lampung & $14,950,000$ & 747,500 & $14,202,500$ & $24,300,000$ & 0 \\
\hline 11 & Province of Jakarta SAR & $28,600,000$ & $1,430,000$ & $27,170,000$ & $24,300,000$ & $2,870,000$ \\
\hline 12 & Province of West Nusa Tenggara & $14,300,000$ & 715,000 & $13,585,000$ & $24,300,000$ & 0 \\
\hline 13 & Province of East Nusa Tenggara & $13,130,000$ & 656,500 & $12,473,500$ & $24,300,000$ & 0 \\
\hline 14 & Province of West Kalimantan & $13,780,000$ & 689,000 & $13,091,000$ & $24,300,000$ & 0 \\
\hline
\end{tabular}


Jurnal Ekonomi Pembangunan, 15 (2), Desember 2014, 172-190

\begin{tabular}{|c|c|c|c|c|c|c|}
\hline & & $\mathrm{A}$ & $\mathrm{B}$ & $\mathrm{C}$ & $\mathrm{D}$ & $\mathrm{E}$ \\
\hline No & Name of Province / Regency / City & $\begin{array}{l}\text { Gross } \\
\text { Income }\end{array}$ & $\begin{array}{l}\text { Official } \\
\text { Expenditure } \\
=\mathrm{A} \times 5 \%\end{array}$ & $\begin{array}{c}\text { Net Income } \\
\quad=\mathrm{A}-\mathrm{B}\end{array}$ & $\begin{array}{c}\text { Personal } \\
\text { Exemption }\end{array}$ & $\begin{array}{l}\text { Assessable } \\
\text { Income } \\
\text { = C - D }\end{array}$ \\
\hline 15 & Province of South Kalimantan & $17,387,500$ & 869,375 & $16,518,125$ & $24,300,000$ & 0 \\
\hline 16 & Province of Central Kalimantan & $20,190,651$ & $1,009,533$ & $19,181,118$ & $24,300,000$ & 0 \\
\hline 17 & Province of East Kalimantan & $22,276,000$ & $1,138,800$ & $21,637,200$ & $24,300,000$ & 0 \\
\hline 18 & Province of Maluku & $16,575,000$ & 828,750 & $15,746,250$ & $24,300,000$ & 0 \\
\hline 19 & Province of North Maluku & $14,983,774$ & 749,189 & $14,234,585$ & $24,300,000$ & 0 \\
\hline 20 & Province of Gorontalo & $15,275,000$ & 763,750 & $14,511,250$ & $24,300,000$ & 0 \\
\hline 21 & Province of North Sulawesi & $20,150,000$ & $1,007,500$ & $19,142,500$ & $24,300,000$ & 0 \\
\hline 22 & Province of South East Sulawesi & $14,625,000$ & 731,250 & $13,893,750$ & $24,300,000$ & 0 \\
\hline 23 & Province of Central Sulawesi & $12,935,000$ & 646,750 & $12,288,250$ & $24,300,000$ & 0 \\
\hline 24 & Province of South Sulawesi & $18,720,000$ & 936,000 & $17,784,000$ & $24,300,000$ & 0 \\
\hline 25 & Province of West Sulawesi & $14,651,000$ & 732,550 & $13,918,450$ & $24,300,000$ & 0 \\
\hline 26 & Province of Papua & $22,230,000$ & $1,111,500$ & $21,118,500$ & $24,300,000$ & 0 \\
\hline 27 & Province of West Papua & $22,360,000$ & $1,118,000$ & $21,242,000$ & $24,300,000$ & 0 \\
\hline 28 & Regency of Tasikmalaya - West Java & $13,455,000$ & 672,750 & $12,782,250$ & $24,300,000$ & 0 \\
\hline 29 & Regency of Ciamis - West Java & $11,102,975$ & 555,149 & $10,547,826$ & $24,300,000$ & 0 \\
\hline 30 & City of Sukabumi - West Java & $13,650,000$ & 682,500 & $12,967,500$ & $24,300,000$ & 0 \\
\hline 31 & Regency of Garut - West Java & $12,545,000$ & 627,250 & $11,917,750$ & $24,300,000$ & 0 \\
\hline 32 & City of Banjar - West Java & $12,350,000$ & 617,500 & $11,732,500$ & $24,300,000$ & 0 \\
\hline 33 & Regency of Majalengka - West Java & $11,050,000$ & 552,500 & $10,497,500$ & $24,300,000$ & 0 \\
\hline 34 & Regency of Sukabumi - West Java & $15,613,260$ & 780,663 & $14,832,597$ & $24,300,000$ & 0 \\
\hline 35 & Regency of Cirebon - West Java & $14,056,900$ & 702,845 & $13,354,055$ & $24,300,000$ & 0 \\
\hline 36 & Regency of Bandung - West Java & $18,048,329$ & 902,416 & $17,145,913$ & $24,300,000$ & 0 \\
\hline 37 & Regency of Sumedang - West Java & $17,962,100$ & 898,105 & $17,063,995$ & $24,300,000$ & 0 \\
\hline 38 & City of Tasikmalaya - West Java & $13,585,000$ & 679,250 & $12,905,750$ & $24,300,000$ & 0 \\
\hline 39 & Regency of Kuningan - West Java & $11,141,000$ & 557,050 & $10,583,950$ & $24,300,000$ & 0 \\
\hline 40 & City of Cirebon - West Java & $14,072,500$ & 703,625 & $13,368,875$ & $24,300,000$ & 0 \\
\hline 41 & Regency of Cianjur - West Java & $12,610,000$ & 630,500 & $11,979,500$ & $24,300,000$ & 0 \\
\hline 42 & City of Bandung - West Java & $20,003,139$ & $1,000,157$ & $19,002,982$ & $24,300,000$ & 0 \\
\hline 43 & Regency of Subang - West Java & $15,860,000$ & 793,000 & $15,067,000$ & $24,300,000$ & 0 \\
\hline 44 & Regency of Bekasi - West Java & $26,026,000$ & $1,301,300$ & $24,724,700$ & $24,300,000$ & 424,000 \\
\hline 45 & Regency of Indramayu - West Java & $14,625,000$ & 731,250 & $13,893,750$ & $24,300,000$ & 0 \\
\hline 46 & City of Cimahi - West Java & $18,048,329$ & 902,416 & $17,145,913$ & $24,300,000$ & 0 \\
\hline 47 & City of Bekasi - West Java & $27,300,000$ & $1,365,000$ & $25,935,000$ & $24,300,000$ & $1,635,000$ \\
\hline 48 & Regency of Purwakarta - West Java & $22,011,171$ & $1,100,559$ & $20,910,612$ & $24,300,000$ & 0 \\
\hline 49 & $\begin{array}{l}\text { Regency of Bandung Barat - West } \\
\text { Java }\end{array}$ & $18,153,187$ & 90 & 8 & 00 & 0 \\
\hline 50 & City of Depok - West Java & $26,546,000$ & $1,327,300$ & $25,218,700$ & $24,300,000$ & 918,000 \\
\hline 51 & Regency of Bogor - West Java & $26,026,000$ & $1,301,300$ & $24,724,700$ & $24,300,000$ & 424,000 \\
\hline 52 & City of Bogor - West Java & $26,026,000$ & $1,301,300$ & $24,724,700$ & $24,300,000$ & 424,000 \\
\hline 53 & Regency of Karawang - West Java & $26,000,000$ & $1,300,000$ & $24,700,000$ & $24,300,000$ & 400,000 \\
\hline 54 & Regency of Lebak - Banten & $15,437,500$ & 771,875 & $14,665,625$ & $24,300,000$ & 0 \\
\hline 55 & City of Serang - Banten & $23,379,798$ & $1,168,990$ & $22,210,808$ & $24,300,000$ & 0 \\
\hline 56 & Regency of Pandeglang - Banten & $15,366,000$ & 768,300 & $14,597,700$ & $24,300,000$ & 0 \\
\hline 57 & City of Tangerang - Banten & $28,639,000$ & $1,431,950$ & $27,207,050$ & $24,300,000$ & $2,907,000$ \\
\hline 58 & Regency of Tangerang - Banten & $28,600,000$ & $1,430,000$ & $27,170,000$ & $24,300,000$ & $2,870,000$ \\
\hline 59 & City of South Tangerang - Banten & $28,600,000$ & $1,430,000$ & $27,170,000$ & $24,300,000$ & $2,870,000$ \\
\hline 60 & City of Cilegon - Banten & $28,600,000$ & $1,430,000$ & $27,170,000$ & $24,300,000$ & $2,870,000$ \\
\hline 61 & Regency of Serang - Banten & $27,040,000$ & $1,352,000$ & $25,688,000$ & $24,300,000$ & $1,388,000$ \\
\hline 62 & City of Semarang - Central Java & $15,718,300$ & 785,915 & $14,932,385$ & $24,300,000$ & 0 \\
\hline 63 & Regency of Demak - Central Java & $12,935,000$ & 646,750 & $12,288,250$ & $24,300,000$ & 0 \\
\hline 64 & Regency of Kendal - Central Java & $12,389,000$ & 619,450 & $11,769,550$ & $24,300,000$ & 0 \\
\hline 65 & Regency of Semarang - Central Java & $13,663,000$ & 683,150 & $12,979,850$ & $24,300,000$ & 0 \\
\hline 66 & City of Salatiga - Central Java & $12,662,000$ & 633,100 & $12,028,900$ & $24,300,000$ & 0 \\
\hline 67 & Regency of Grobogan - Central Java & $10,946,000$ & 547,300 & $10,398,700$ & $24,300,000$ & 0 \\
\hline 68 & Regency of Blora - Central Java & $12,116,000$ & 605,800 & $11,510,200$ & $24,300,000$ & 0 \\
\hline 69 & Regency of Kudus - Central Java & $12,870,000$ & 643,500 & $12,226,500$ & $24,300,000$ & 0 \\
\hline 70 & Regency of Jepara - Central Java & $11,375,000$ & 568,750 & $10,806,250$ & $24,300,000$ & 0 \\
\hline 71 & Regency of Pati - Central Java & $12,058,800$ & 602,940 & $11,455,860$ & $24,300,000$ & 0 \\
\hline 72 & Regency of Rembang - Central Java & $11,648,000$ & 582,400 & $11,065,600$ & $24,300,000$ & 0 \\
\hline 73 & Regency of Boyolali - Central Java & $11,635,000$ & 581,750 & $11,053,250$ & $24,300,000$ & 0 \\
\hline 74 & City of Surakarta - Central Java & $11,906,700$ & 595,335 & $11,311,365$ & $24,300,000$ & 0 \\
\hline 75 & Regency of Sukoharjo - Central Java & $11,726,000$ & 586,300 & $11,139,700$ & $24,300,000$ & 0 \\
\hline 76 & Regency of Sragen - Central Java & $11,232,000$ & 561,600 & $10,670,400$ & $24,300,000$ & 0 \\
\hline
\end{tabular}


Jurnal Ekonomi Pembangunan, 15 (2), Desember 2014, 172-190

\begin{tabular}{|c|c|c|c|c|c|c|}
\hline & & $\mathrm{A}$ & $\mathrm{B}$ & $\mathrm{C}$ & $\mathrm{D}$ & $\mathrm{E}$ \\
\hline No & Name of Province / Regency / City & $\begin{array}{l}\text { Gross } \\
\text { Income }\end{array}$ & $\begin{array}{c}\text { Official } \\
\text { Expenditure } \\
=\mathrm{A} \times 5 \%\end{array}$ & $\begin{array}{c}\text { Net Income } \\
=\mathrm{A}-\mathrm{B}\end{array}$ & $\begin{array}{l}\text { Personal } \\
\text { Exemption }\end{array}$ & $\begin{array}{c}\text { Assessable } \\
\text { Income } \\
=\mathrm{C}-\mathrm{D}\end{array}$ \\
\hline 77 & $\begin{array}{l}\text { Regency of Karanganyar - Central } \\
\text { Java }\end{array}$ & $11,654,500$ & 582,725 & $11,071,775$ & $24,300,000$ & 0 \\
\hline 78 & Regency of Wonogiri - Central Java & $10,790,000$ & 539,500 & $10,250,500$ & $24,300,000$ & 0 \\
\hline 79 & Regency of Klaten - Central Java & $11,329,500$ & 566,475 & $10,763,025$ & $24,300,000$ & 0 \\
\hline 80 & City of Magelang - Central Java & $11,719,500$ & 585,975 & $11,133,525$ & $24,300,000$ & 0 \\
\hline 81 & Regency of Magelang - Central Java & $12,246,000$ & 612,300 & $11,633,700$ & $24,300,000$ & 0 \\
\hline 82 & Regency of Purworejo - Central Java & $11,037,000$ & 551,850 & $10,485,150$ & $24,300,000$ & 0 \\
\hline 83 & $\begin{array}{l}\text { Regency ofTemanggung - Central } \\
\text { Java }\end{array}$ & $12,220,000$ & 611,000 & $11,609,000$ & $24,300,000$ & 0 \\
\hline 84 & Regency of Wonosobo - Central Java & $11,440,000$ & 572,000 & $10,868,000$ & $24,300,000$ & 0 \\
\hline 85 & Regency of Kebumen - Central Java & $10,855,000$ & 542,750 & $10,312,250$ & $24,300,000$ & 0 \\
\hline 86 & Regency of Banyumas - Central Java & $11,407,500$ & 570,375 & $10,837,125$ & $24,300,000$ & 0 \\
\hline 87 & $\begin{array}{l}\text { Regency of Cilacap City - Central } \\
\text { Java }\end{array}$ & $12,818,000$ & 640,900 & $12,177,100$ & $24,300,000$ & 0 \\
\hline 88 & $\begin{array}{l}\text { Regency of East Cilacap - Central } \\
\text { Java }\end{array}$ & $11,193,000$ & 559,650 & $10,633,350$ & $24,300,000$ & 0 \\
\hline 89 & $\begin{array}{l}\text { Regency of West Cilacap - Central } \\
\text { Java }\end{array}$ & $10,608,000$ & 530,400 & $10,077,600$ & $24,300,000$ & 0 \\
\hline 90 & $\begin{array}{l}\text { Regency of Banjarnegara - Central } \\
\text { Java }\end{array}$ & $10,855,000$ & 542,750 & $10,312,250$ & $24,300,000$ & 0 \\
\hline 91 & $\begin{array}{l}\text { Regency of Purbalingga - Central } \\
\text { Java }\end{array}$ & $11,654,500$ & 582,725 & $11,071,775$ & $24,300,000$ & 0 \\
\hline 92 & Regency of Batang - Central Java & $12,610,000$ & 630,500 & $11,979,500$ & $24,300,000$ & 0 \\
\hline 93 & City of Pekalongan - Central Java & $12,740,000$ & 637,000 & $12,103,000$ & $24,300,000$ & 0 \\
\hline 94 & $\begin{array}{l}\text { Regency of Pekalongan - Central } \\
\text { Java }\end{array}$ & $12,506,000$ & 625,300 & $11,880,700$ & $24,300,000$ & 0 \\
\hline 95 & Regency of Pemalang - Central Java & $11,804,000$ & 590,200 & $11,213,800$ & $24,300,000$ & 0 \\
\hline 96 & City of Tegal - Central Java & $11,180,000$ & 559,000 & $10,621,000$ & $24,300,000$ & 0 \\
\hline 97 & Regency of Tegal - Central Java & $11,180,000$ & 559,000 & $10,621,000$ & $24,300,000$ & 0 \\
\hline 98 & Regency of Brebes - Central Java & $11,167,000$ & 558,350 & $10,608,650$ & $24,300,000$ & 0 \\
\hline 99 & $\begin{array}{l}\text { City of Yogyakarta - Yogyakarta } \\
\text { SAR }\end{array}$ & $13,848,211$ & 692,411 & $13,155,800$ & $24,300,000$ & 0 \\
\hline 100 & $\begin{array}{l}\text { Regency of Sleman - Yogyakarta } \\
\text { SAR }\end{array}$ & $13,340,353$ & 667,018 & $12,673,335$ & $24,300,000$ & 0 \\
\hline 101 & Regency of Bantul - Yogyakarta SAR & $12,915,292$ & 645,765 & $12,269,527$ & $24,300,000$ & 0 \\
\hline 102 & $\begin{array}{l}\text { Regency of Kulon Progo - Yogyakarta } \\
\text { SAR }\end{array}$ & $12,406,407$ & 620,320 & $11,786,087$ & $24,300,000$ & 0 \\
\hline 103 & $\begin{array}{l}\text { Regency of Gunung Kidul - } \\
\text { Yogyakarta SAR }\end{array}$ & $12,312,482$ & 615,624 & $11,696,858$ & $24,300,000$ & 0 \\
\hline 104 & City of Surabaya - East Java & $22,620,000$ & $1,131,000$ & $21,489,000$ & $24,300,000$ & 0 \\
\hline 105 & Regency of Gresik - East Java & $22,620,000$ & $1,131,000$ & $21,489,000$ & $24,300,000$ & 0 \\
\hline 106 & Regency of Pasuruan - East Java & $22,360,000$ & $1,118,000$ & $21,242,000$ & $24,300,000$ & 0 \\
\hline 107 & Regency of Sidoarjo - East Java & $22,360,000$ & $1,118,000$ & $21,242,000$ & $24,300,000$ & 0 \\
\hline 108 & Regency of Mojokerto - East Java & $22,100,000$ & $1,105,000$ & $20,995,000$ & $24,300,000$ & 0 \\
\hline 109 & Regency of Malang - East Java & $17,468,100$ & 873,405 & $16,594,695$ & $24,300,000$ & 0 \\
\hline 110 & City of Malang - East Java & $17,423,900$ & 871,195 & $16,552,705$ & $24,300,000$ & 0 \\
\hline 111 & City of Batu - East Java & $16,484,000$ & 824,200 & $15,659,800$ & $24,300,000$ & 0 \\
\hline 112 & Regency of Jombang - East Java & $15,600,000$ & 780,000 & $14,820,000$ & $24,300,000$ & 0 \\
\hline 113 & Regency of Probolinggo - East Java & $15,581,800$ & 779,090 & $14,802,710$ & $24,300,000$ & 0 \\
\hline 114 & City of Pasuruan - East Java & $15,545,400$ & 777,270 & $14,768,130$ & $24,300,000$ & 0 \\
\hline 115 & Regency of Tuban - East Java & $14,877,200$ & 743,860 & $14,133,340$ & $24,300,000$ & 0 \\
\hline 116 & City of Kediri - East Java & $14,669,200$ & 733,460 & $13,935,740$ & $24,300,000$ & 0 \\
\hline 117 & Regency of Sampang - East Java & $14,359,800$ & 717,990 & $13,641,810$ & $24,300,000$ & 0 \\
\hline 118 & City of Probolinggo - East Java & $14,341,600$ & 717,080 & $13,624,520$ & $24,300,000$ & 0 \\
\hline 119 & Regency of Jember - East Java & $14,195,350$ & 709,768 & $13,485,583$ & $24,300,000$ & 0 \\
\hline 120 & Regency of Kediri - East Java & $14,169,350$ & 708,468 & $13,460,883$ & $24,300,000$ & 0 \\
\hline 121 & Regency of Banyuwangi - East Java & $14,123,200$ & 706,160 & $13,417,040$ & $24,300,000$ & 0 \\
\hline 122 & Regency of Lamongan - East Java & $13,984,100$ & 699,205 & $13,284,895$ & $24,300,000$ & 0 \\
\hline 123 & Regency of Pamekasan - East Java & $13,774,800$ & 688,740 & $13,086,060$ & $24,300,000$ & 0 \\
\hline 124 & Regency of Situbondo - East Java & $13,624,000$ & 681,200 & $12,942,800$ & $24,300,000$ & 0 \\
\hline 125 & City of Mojokerto - East Java & $13,520,000$ & 676,000 & $12,844,000$ & $24,300,000$ & 0 \\
\hline 126 & Regency of Bojonegoro - East Java & $13,383,500$ & 669,175 & $12,714,325$ & $24,300,000$ & 0 \\
\hline
\end{tabular}


Jurnal Ekonomi Pembangunan, 15 (2), Desember 2014, 172-190

\begin{tabular}{|c|c|c|c|c|c|c|}
\hline & & $\mathrm{A}$ & $\mathrm{B}$ & $\mathrm{C}$ & $\mathrm{D}$ & $\mathrm{E}$ \\
\hline No & Name of Province / Regency / City & $\begin{array}{l}\text { Gross } \\
\text { Income }\end{array}$ & $\begin{array}{l}\text { Official } \\
\text { Expenditure } \\
=\mathrm{A} \times 5 \%\end{array}$ & $\begin{array}{c}\text { Net Income } \\
\quad=\mathrm{A}-\mathrm{B}\end{array}$ & $\begin{array}{c}\text { Personal } \\
\text { Exemption }\end{array}$ & $\begin{array}{c}\text { Assessable } \\
\text { Income } \\
=\mathrm{C}-\mathrm{D}\end{array}$ \\
\hline 127 & Regency of Lumajang - East Java & $13,155,350$ & 657,768 & $12,497,583$ & $24,300,000$ & 0 \\
\hline 128 & Regency of Tulungagung - East Java & $13,102,700$ & 655,135 & $12,447,565$ & $24,300,000$ & 0 \\
\hline 129 & Regency of Bangkalan - East Java & $12,789,400$ & 639,470 & $12,149,930$ & $24,300,000$ & 0 \\
\hline 130 & Regency of Sumenep - East Java & $12,545,000$ & 627,250 & $11,917,750$ & $24,300,000$ & 0 \\
\hline 131 & Regency of Madiun - East Java & $12,489,750$ & 624,488 & $11,865,263$ & $24,300,000$ & 0 \\
\hline 132 & Regency of Nganjuk - East Java & $12,482,600$ & 624,130 & $11,858,470$ & $24,300,000$ & 0 \\
\hline 133 & City of Madiun - East Java & $12,389,000$ & 619,450 & $11,769,550$ & $24,300,000$ & 0 \\
\hline 134 & Regency of Blitar - East Java & $12,309,050$ & 615,453 & $11,693,598$ & $24,300,000$ & 0 \\
\hline 135 & Regency of Bondowoso - East Java & $12,298,000$ & 614,900 & $11,683,100$ & $24,300,000$ & 0 \\
\hline 136 & City of Blitar - East Java & $12,022,400$ & 601,120 & $11,421,280$ & $24,300,000$ & 0 \\
\hline 137 & Regency of Ponorogo - East Java & $12,012,000$ & 600,600 & $11,411,400$ & $24,300,000$ & 0 \\
\hline 138 & Regency of Trenggalek - East Java & $11,750,700$ & 587,535 & $11,163,165$ & $24,300,000$ & 0 \\
\hline 139 & Regency of Ngawi - East Java & $11,700,000$ & 585,000 & $11,115,000$ & $24,300,000$ & 0 \\
\hline 140 & Regency of Pacitan - East Java & $11,534,250$ & 576,713 & $10,957,538$ & $24,300,000$ & 0 \\
\hline 141 & Regency of Magetan - East Java & $11,261,250$ & 563,063 & $10,698,188$ & $24,300,000$ & 0 \\
\hline 142 & Regency of Badung - Bali & $18,213,000$ & 910,650 & $17,302,350$ & $24,300,000$ & 0 \\
\hline 143 & City of Denpasar - Bali & $17,654,000$ & 882,700 & $16,771,300$ & $24,300,000$ & 0 \\
\hline 144 & Regency of Gianyar - Bali & $15,990,000$ & 799,500 & $15,190,500$ & $24,300,000$ & 0 \\
\hline 145 & Regency of Karangasem - Bali & $15,535,000$ & 776,750 & $14,758,250$ & $24,300,000$ & 0 \\
\hline 146 & Regency of Jembrana - Bali & $15,762,500$ & 788,125 & $14,974,375$ & $24,300,000$ & 0 \\
\hline 147 & Regency of Tabanan - Bali & $16,250,000$ & 812,500 & $15,437,500$ & $24,300,000$ & 0 \\
\hline 148 & Regency of Klungkung - Bali & $15,470,000$ & 773,500 & $14,696,500$ & $24,300,000$ & 0 \\
\hline 149 & Regency of Buleleng - Bali & $15,600,000$ & 780,000 & $14,820,000$ & $24,300,000$ & 0 \\
\hline 150 & Regency of Bangli - Bali & $15,366,000$ & 768,300 & $14,597,700$ & $24,300,000$ & 0 \\
\hline 151 & $\begin{array}{l}\text { City of Pontianak - West } \\
\text { Kalimantan }\end{array}$ & $15,145,000$ & 757,250 & $14,387,750$ & $24,300,000$ & 0 \\
\hline 152 & City of Makassar - South Sulawesi & $19,500,000$ & 975,000 & $18,525,000$ & $24,300,000$ & 0 \\
\hline
\end{tabular}

Table 4. Workers' Assessable Income in 2013 (in Rupiah)

\begin{tabular}{|c|c|c|c|c|c|c|}
\hline & & A & B & $\mathrm{C}$ & $\mathrm{D}$ & $\mathrm{E}$ \\
\hline No & Name of Province / Regency / City & $\begin{array}{l}\text { Gross } \\
\text { Income }\end{array}$ & $\begin{array}{l}\text { Official } \\
\text { Expendi- } \\
\text { ture } \\
=\mathrm{A} \times 5 \%\end{array}$ & $\begin{array}{c}\text { Net } \\
\text { Income } \\
=\mathrm{A}-\mathrm{B}\end{array}$ & $\begin{array}{c}\text { Personal } \\
\text { Exemption }\end{array}$ & $\begin{array}{l}\text { Assessable } \\
\text { Income } \\
\text { = C - D }\end{array}$ \\
\hline 1 & Province of Nanggroe Aceh Darussalam & $20,150,000$ & $1,007,500$ & $19,142,500$ & $24,300,000$ & 0 \\
\hline 2 & Province of North Sumatera & $16,965,000$ & 848,250 & $16,116,750$ & $24,300,000$ & 0 \\
\hline 3 & Province of West Sumatera & $17,550,000$ & 877,500 & $16,672,500$ & $24,300,000$ & 0 \\
\hline 4 & Province of Riau & $18,200,000$ & 910,000 & $17,290,000$ & $24,300,000$ & 0 \\
\hline 5 & Province of Riau Islands & $17,746,131$ & 887,307 & $16,858,824$ & $24,300,000$ & 0 \\
\hline 6 & Province of Jambi & $16,900,000$ & 845,000 & $16,055,000$ & $24,300,000$ & 0 \\
\hline 7 & Province of South Sumatera & $17,550,000$ & 877,500 & $16,672,500$ & $24,300,000$ & 0 \\
\hline 8 & Province of Bangka - Belitung & $21,091,200$ & $1,054,560$ & $20,036,640$ & $24,300,000$ & 0 \\
\hline 9 & Province of Bengkulu & $15,600,000$ & 780,000 & $14,820,000$ & $24,300,000$ & 0 \\
\hline 10 & Province of Lampung & $14,950,000$ & 747,500 & $14,202,500$ & $24,300,000$ & 0 \\
\hline 11 & Province of Jakarta SAR & $28,600,000$ & $1,430,000$ & $27,170,000$ & $24,300,000$ & $2,870,000$ \\
\hline 12 & Province of West Nusa Tenggara & $14,300,000$ & 715,000 & $13,585,000$ & $24,300,000$ & 0 \\
\hline 13 & Province of East Nusa Tenggara & $13,130,000$ & 656,500 & $12,473,500$ & $24,300,000$ & 0 \\
\hline 14 & Province of West Kalimantan & $13,780,000$ & 689,000 & $13,091,000$ & $24,300,000$ & 0 \\
\hline 15 & Province of South Kalimantan & $17,387,500$ & 869,375 & $16,518,125$ & $24,300,000$ & 0 \\
\hline 16 & Province of Central Kalimantan & $20,190,651$ & $1,009,533$ & $19,181,118$ & $24,300,000$ & 0 \\
\hline 17 & Province of East Kalimantan & $22,276,000$ & $1,138,800$ & $21,637,200$ & $24,300,000$ & 0 \\
\hline 18 & Province of Maluku & $16,575,000$ & 828,750 & $15,746,250$ & $24,300,000$ & 0 \\
\hline 19 & Province of North Maluku & $14,983,774$ & 749,189 & $14,234,585$ & $24,300,000$ & 0 \\
\hline 20 & Province of Gorontalo & $15,275,000$ & 763,750 & $14,511,250$ & $24,300,000$ & 0 \\
\hline 21 & Province of North Sulawesi & $20,150,000$ & $1,007,500$ & $19,142,500$ & $24,300,000$ & 0 \\
\hline 22 & Province of South East Sulawesi & $14,625,000$ & 731,250 & $13,893,750$ & $24,300,000$ & 0 \\
\hline 23 & Province of Central Sulawesi & $12,935,000$ & 646,750 & $12,288,250$ & $24,300,000$ & 0 \\
\hline 24 & Province of South Sulawesi & $18,720,000$ & 936,000 & $17,784,000$ & $24,300,000$ & 0 \\
\hline 25 & Province of West Sulawesi & $14,651,000$ & 732,550 & $13,918,450$ & $24,300,000$ & 0 \\
\hline 26 & Province of Papua & $22,230,000$ & $1,111,500$ & $21,118,500$ & $24,300,000$ & 0 \\
\hline 27 & Province of West Papua & $22,360,000$ & $1,118,000$ & $21,242,000$ & $24,300,000$ & 0 \\
\hline
\end{tabular}


Jurnal Ekonomi Pembangunan, 15 (2), Desember 2014, 172-190

\begin{tabular}{|c|c|c|c|c|c|c|}
\hline & & $\mathrm{A}$ & $\mathrm{B}$ & $\mathrm{C}$ & $\mathrm{D}$ & $\mathrm{E}$ \\
\hline No & Name of Province / Regency / City & $\begin{array}{l}\text { Gross } \\
\text { Income }\end{array}$ & $\begin{array}{l}\text { Official } \\
\text { Expendi- } \\
\text { ture } \\
=\mathrm{A} \times 5 \%\end{array}$ & $\begin{array}{c}\text { Net } \\
\text { Income } \\
=\mathrm{A}-\mathrm{B}\end{array}$ & $\begin{array}{c}\text { Personal } \\
\text { Exemption }\end{array}$ & $\begin{array}{l}\text { Assessable } \\
\text { Income } \\
\text { = C - D }\end{array}$ \\
\hline 28 & Regency of Tasikmalaya - West Java & $13,455,000$ & 672,750 & $12,782,250$ & $24,300,000$ & 0 \\
\hline 29 & Regency of Ciamis - West Java & $11,102,975$ & 555,149 & $10,547,826$ & $24,300,000$ & 0 \\
\hline 30 & City of Sukabumi - West Java & $13,650,000$ & 682,500 & $12,967,500$ & $24,300,000$ & 0 \\
\hline 31 & Regency of Garut - West Java & $12,545,000$ & 627,250 & $11,917,750$ & $24,300,000$ & 0 \\
\hline 32 & City of Banjar - West Java & $12,350,000$ & 617,500 & $11,732,500$ & $24,300,000$ & 0 \\
\hline 33 & Regency of Majalengka - West Java & $11,050,000$ & 552,500 & $10,497,500$ & $24,300,000$ & 0 \\
\hline 34 & Regency of Sukabumi - West Java & $15,613,260$ & 780,663 & $14,832,597$ & $24,300,000$ & 0 \\
\hline 35 & Regency of Cirebon - West Java & $14,056,900$ & 702,845 & $13,354,055$ & $24,300,000$ & 0 \\
\hline 36 & Regency of Bandung - West Java & $18,048,329$ & 902,416 & $17,145,913$ & $24,300,000$ & 0 \\
\hline 37 & Regency of Sumedang - West Java & $17,962,100$ & 898,105 & $17,063,995$ & $24,300,000$ & 0 \\
\hline 38 & City of Tasikmalaya - West Java & $13,585,000$ & 679,250 & $12,905,750$ & $24,300,000$ & 0 \\
\hline 39 & Regency of Kuningan - West Java & $11,141,000$ & 557,050 & $10,583,950$ & $24,300,000$ & 0 \\
\hline 40 & City of Cirebon - West Java & $14,072,500$ & 703,625 & $13,368,875$ & $24,300,000$ & 0 \\
\hline 41 & Regency of Cianjur - West Java & $12,610,000$ & 630,500 & $11,979,500$ & $24,300,000$ & 0 \\
\hline 42 & City of Bandung - West Java & $20,003,139$ & $1,000,157$ & $19,002,982$ & $24,300,000$ & 0 \\
\hline 43 & Regency of Subang - West Java & $15,860,000$ & 793,000 & $15,067,000$ & $24,300,000$ & 0 \\
\hline 44 & Regency of Bekasi - West Java & $26,026,000$ & $1,301,300$ & $24,724,700$ & $24,300,000$ & 424,000 \\
\hline 45 & Regency of Indramayu - West Java & $14,625,000$ & 731,250 & $13,893,750$ & $24,300,000$ & 0 \\
\hline 46 & City of Cimahi - West Java & $18,048,329$ & 902,416 & $17,145,913$ & $24,300,000$ & 0 \\
\hline 47 & City of Bekasi - West Java & $27,300,000$ & $1,365,000$ & $25,935,000$ & $24,300,000$ & $1,635,000$ \\
\hline 48 & Regency of Purwakarta - West Java & $22,011,171$ & $1,100,559$ & $20,910,612$ & $24,300,000$ & 0 \\
\hline 49 & Regency of Bandung Barat - West Java & $18,153,187$ & 907,659 & $17,245,528$ & $24,300,000$ & 0 \\
\hline 50 & City of Depok - West Java & $26,546,000$ & $1,327,300$ & $25,218,700$ & $24,300,000$ & 918,000 \\
\hline 51 & Regency of Bogor - West Java & $26,026,000$ & $1,301,300$ & $24,724,700$ & $24,300,000$ & 424,000 \\
\hline 52 & City of Bogor - West Java & $26,026,000$ & $1,301,300$ & $24,724,700$ & $24,300,000$ & 424,000 \\
\hline 53 & Regency of Karawang - West Java & $26,000,000$ & $1,300,000$ & $24,700,000$ & $24,300,000$ & 400,000 \\
\hline 54 & Regency of Lebak - Banten & $15,437,500$ & 771,875 & $14,665,625$ & $24,300,000$ & 0 \\
\hline 55 & City of Serang - Banten & $23,379,798$ & $1,168,990$ & $22,210,808$ & $24,300,000$ & 0 \\
\hline 56 & Regency of Pandeglang - Banten & $15,366,000$ & 768,300 & $14,597,700$ & $24,300,000$ & 0 \\
\hline 57 & City of Tangerang - Banten & $28,639,000$ & $1,431,950$ & $27,207,050$ & $24,300,000$ & $2,907,000$ \\
\hline 58 & Regency of Tangerang - Banten & $28,600,000$ & $1,430,000$ & $27,170,000$ & $24,300,000$ & $2,870,000$ \\
\hline 59 & City of South Tangerang - Banten & $28,600,000$ & $1,430,000$ & $27,170,000$ & $24,300,000$ & $2,870,000$ \\
\hline 60 & City of Cilegon - Banten & $28,600,000$ & $1,430,000$ & $27,170,000$ & $24,300,000$ & $2,870,000$ \\
\hline 61 & Regency of Serang - Banten & $27,040,000$ & $1,352,000$ & $25,688,000$ & $24,300,000$ & $1,388,000$ \\
\hline 62 & City of Semarang - Central Java & $15,718,300$ & 785,915 & $14,932,385$ & $24,300,000$ & 0 \\
\hline 63 & Regency of Demak - Central Java & $12,935,000$ & 646,750 & $12,288,250$ & $24,300,000$ & 0 \\
\hline 64 & Regency of Kendal - Central Java & $12,389,000$ & 619,450 & $11,769,550$ & $24,300,000$ & 0 \\
\hline 65 & Regency of Semarang - Central Java & $13,663,000$ & 683,150 & $12,979,850$ & $24,300,000$ & 0 \\
\hline 66 & City of Salatiga - Central Java & $12,662,000$ & 633,100 & $12,028,900$ & $24,300,000$ & 0 \\
\hline 67 & Regency of Grobogan - Central Java & $10,946,000$ & 547,300 & $10,398,700$ & $24,300,000$ & 0 \\
\hline 68 & Regency of Blora - Central Java & $12,116,000$ & 605,800 & $11,510,200$ & $24,300,000$ & 0 \\
\hline 69 & Regency of Kudus - Central Java & $12,870,000$ & 643,500 & $12,226,500$ & $24,300,000$ & 0 \\
\hline 70 & Regency of Jepara - Central Java & $11,375,000$ & 568,750 & $10,806,250$ & $24,300,000$ & 0 \\
\hline 71 & Regency of Pati - Central Java & $12,058,800$ & 602,940 & $11,455,860$ & $24,300,000$ & 0 \\
\hline 72 & Regency of Rembang - Central Java & $11,648,000$ & 582,400 & $11,065,600$ & $24,300,000$ & 0 \\
\hline 73 & Regency of Boyolali - Central Java & $11,635,000$ & 581,750 & $11,053,250$ & $24,300,000$ & 0 \\
\hline 74 & City of Surakarta - Central Java & $11,906,700$ & 595,335 & $11,311,365$ & $24,300,000$ & 0 \\
\hline 75 & Regency of Sukoharjo - Central Java & $11,726,000$ & 586,300 & $11,139,700$ & $24,300,000$ & 0 \\
\hline 76 & Regency of Sragen - Central Java & $11,232,000$ & 561,600 & $10,670,400$ & $24,300,000$ & 0 \\
\hline 77 & Regency of Karanganyar - Central Java & $11,654,500$ & 582,725 & $11,071,775$ & $24,300,000$ & 0 \\
\hline 78 & Regency of Wonogiri - Central Java & $10,790,000$ & 539,500 & $10,250,500$ & $24,300,000$ & 0 \\
\hline 79 & Regency of Klaten - Central Java & $11,329,500$ & 566,475 & $10,763,025$ & $24,300,000$ & 0 \\
\hline 80 & City of Magelang - Central Java & $11,719,500$ & 585,975 & $11,133,525$ & $24,300,000$ & 0 \\
\hline 81 & Regency of Magelang - Central Java & $12,246,000$ & 612,300 & $11,633,700$ & $24,300,000$ & 0 \\
\hline 82 & Regency of Purworejo - Central Java & $11,037,000$ & 551,850 & $10,485,150$ & $24,300,000$ & 0 \\
\hline 83 & Regency ofTemanggung - Central Java & $12,220,000$ & 611,000 & $11,609,000$ & $24,300,000$ & 0 \\
\hline 84 & Regency of Wonosobo - Central Java & $11,440,000$ & 572,000 & $10,868,000$ & $24,300,000$ & 0 \\
\hline 85 & Regency of Kebumen - Central Java & $10,855,000$ & 542,750 & $10,312,250$ & $24,300,000$ & 0 \\
\hline 86 & Regency of Banyumas - Central Java & $11,407,500$ & 570,375 & $10,837,125$ & $24,300,000$ & 0 \\
\hline 87 & Regency of Cilacap City - Central Java & $12,818,000$ & 640,900 & $12,177,100$ & $24,300,000$ & 0 \\
\hline 88 & Regency of East Cilacap - Central Java & $11,193,000$ & 559,650 & $10,633,350$ & $24,300,000$ & 0 \\
\hline 89 & Regency of West Cilacap - Central Java & $10,608,000$ & 530,400 & $10,077,600$ & $24,300,000$ & \\
\hline
\end{tabular}


Jurnal Ekonomi Pembangunan, 15 (2), Desember 2014, 172-190

\begin{tabular}{|c|c|c|c|c|c|c|}
\hline & & $\mathrm{A}$ & $\mathrm{B}$ & $\mathrm{C}$ & $\mathrm{D}$ & $\mathrm{E}$ \\
\hline No & Name of Province / Regency / City & $\begin{array}{l}\text { Gross } \\
\text { Income }\end{array}$ & $\begin{array}{l}\text { Official } \\
\text { Expendi- } \\
\text { ture } \\
=\mathrm{A} \times 5 \%\end{array}$ & $\begin{array}{c}\text { Net } \\
\text { Income } \\
=\mathrm{A}-\mathrm{B}\end{array}$ & $\begin{array}{c}\text { Personal } \\
\text { Exemption }\end{array}$ & $\begin{array}{l}\text { Assessable } \\
\text { Income } \\
\text { = C - D }\end{array}$ \\
\hline 90 & Regency of Banjarnegara - Central Java & $10,855,000$ & 542,750 & $10,312,250$ & $24,300,000$ & 0 \\
\hline 91 & Regency of Purbalingga - Central Java & $11,654,500$ & 582,725 & $11,071,775$ & $24,300,000$ & 0 \\
\hline 92 & Regency of Batang - Central Java & $12,610,000$ & 630,500 & $11,979,500$ & $24,300,000$ & 0 \\
\hline 93 & City of Pekalongan - Central Java & $12,740,000$ & 637,000 & $12,103,000$ & $24,300,000$ & 0 \\
\hline 94 & Regency of Pekalongan - Central Java & $12,506,000$ & 625,300 & $11,880,700$ & $24,300,000$ & 0 \\
\hline 95 & Regency of Pemalang - Central Java & $11,804,000$ & 590,200 & $11,213,800$ & $24,300,000$ & 0 \\
\hline 96 & City of Tegal - Central Java & $11,180,000$ & 559,000 & $10,621,000$ & $24,300,000$ & 0 \\
\hline 97 & Regency of Tegal - Central Java & $11,180,000$ & 559,000 & $10,621,000$ & $24,300,000$ & 0 \\
\hline 98 & Regency of Brebes - Central Java & $11,167,000$ & 558,350 & $10,608,650$ & $24,300,000$ & 0 \\
\hline 99 & City of Yogyakarta - Yogyakarta SAR & $13,848,211$ & 692,411 & $13,155,800$ & $24,300,000$ & 0 \\
\hline 100 & Regency of Sleman - Yogyakarta SAR & $13,340,353$ & 667,018 & $12,673,335$ & $24,300,000$ & 0 \\
\hline 101 & Regency of Bantul - Yogyakarta SAR & $12,915,292$ & 645,765 & $12,269,527$ & $24,300,000$ & 0 \\
\hline 102 & Regency of Kulon Progo - Yogyakarta SAR & $12,406,407$ & 620,320 & $11,786,087$ & $24,300,000$ & 0 \\
\hline 103 & Regency of Gunung Kidul - Yogyakarta SAR & $12,312,482$ & 615,624 & $11,696,858$ & $24,300,000$ & 0 \\
\hline 104 & City of Surabaya - East Java & $22,620,000$ & $1,131,000$ & $21,489,000$ & $24,300,000$ & 0 \\
\hline 105 & Regency of Gresik - East Java & $22,620,000$ & $1,131,000$ & $21,489,000$ & $24,300,000$ & 0 \\
\hline 106 & Regency of Pasuruan - East Java & $22,360,000$ & $1,118,000$ & $21,242,000$ & $24,300,000$ & 0 \\
\hline 107 & Regency of Sidoarjo - East Java & $22,360,000$ & $1,118,000$ & $21,242,000$ & $24,300,000$ & 0 \\
\hline 108 & Regency of Mojokerto - East Java & $22,100,000$ & $1,105,000$ & $20,995,000$ & $24,300,000$ & 0 \\
\hline 109 & Regency of Malang - East Java & $17,468,100$ & 873,405 & $16,594,695$ & $24,300,000$ & 0 \\
\hline 110 & City of Malang - East Java & $17,423,900$ & 871,195 & $16,552,705$ & $24,300,000$ & 0 \\
\hline 111 & City of Batu - East Java & $16,484,000$ & 824,200 & $15,659,800$ & $24,300,000$ & 0 \\
\hline 112 & Regency of Jombang - East Java & $15,600,000$ & 780,000 & $14,820,000$ & $24,300,000$ & 0 \\
\hline 113 & Regency of Probolinggo - East Java & $15,581,800$ & 779,090 & $14,802,710$ & $24,300,000$ & 0 \\
\hline 114 & City of Pasuruan - East Java & $15,545,400$ & 777,270 & $14,768,130$ & $24,300,000$ & 0 \\
\hline 115 & Regency of Tuban - East Java & $14,877,200$ & 743,860 & $14,133,340$ & $24,300,000$ & 0 \\
\hline 116 & City of Kediri - East Java & $14,669,200$ & 733,460 & $13,935,740$ & $24,300,000$ & 0 \\
\hline 117 & Regency of Sampang - East Java & $14,359,800$ & 717,990 & $13,641,810$ & $24,300,000$ & 0 \\
\hline 118 & City of Probolinggo - East Java & $14,341,600$ & 717,080 & $13,624,520$ & $24,300,000$ & 0 \\
\hline 119 & Regency of Jember - East Java & $14,195,350$ & 709,768 & $13,485,583$ & $24,300,000$ & 0 \\
\hline 120 & Regency of Kediri - East Java & $14,169,350$ & 708,468 & $13,460,883$ & $24,300,000$ & 0 \\
\hline 121 & Regency of Banyuwangi - East Java & $14,123,200$ & 706,160 & $13,417,040$ & $24,300,000$ & 0 \\
\hline 122 & Regency of Lamongan - East Java & $13,984,100$ & 699,205 & $13,284,895$ & $24,300,000$ & 0 \\
\hline 123 & Regency of Pamekasan - East Java & $13,774,800$ & 688,740 & $13,086,060$ & $24,300,000$ & 0 \\
\hline 124 & Regency of Situbondo - East Java & $13,624,000$ & 681,200 & $12,942,800$ & $24,300,000$ & 0 \\
\hline 125 & City of Mojokerto - East Java & $13,520,000$ & 676,000 & $12,844,000$ & $24,300,000$ & 0 \\
\hline 126 & Regency of Bojonegoro - East Java & $13,383,500$ & 669,175 & $12,714,325$ & $24,300,000$ & 0 \\
\hline 127 & Regency of Lumajang - East Java & $13,155,350$ & 657,768 & $12,497,583$ & $24,300,000$ & 0 \\
\hline 128 & Regency of Tulungagung - East Java & $13,102,700$ & 655,135 & $12,447,565$ & $24,300,000$ & 0 \\
\hline 129 & Regency of Bangkalan - East Java & $12,789,400$ & 639,470 & $12,149,930$ & $24,300,000$ & 0 \\
\hline 130 & Regency of Sumenep - East Java & $12,545,000$ & 627,250 & $11,917,750$ & $24,300,000$ & 0 \\
\hline 131 & Regency of Madiun - East Java & $12,489,750$ & 624,488 & $11,865,263$ & $24,300,000$ & 0 \\
\hline 132 & Regency of Nganjuk - East Java & $12,482,600$ & 624,130 & $11,858,470$ & $24,300,000$ & 0 \\
\hline 133 & City of Madiun - East Java & $12,389,000$ & 619,450 & $11,769,550$ & $24,300,000$ & 0 \\
\hline 134 & Regency of Blitar - East Java & $12,309,050$ & 615,453 & $11,693,598$ & $24,300,000$ & 0 \\
\hline 135 & Regency of Bondowoso - East Java & $12,298,000$ & 614,900 & $11,683,100$ & $24,300,000$ & 0 \\
\hline 136 & City of Blitar - East Java & $12,022,400$ & 601,120 & $11,421,280$ & $24,300,000$ & 0 \\
\hline 137 & Regency of Ponorogo - East Java & $12,012,000$ & 600,600 & $11,411,400$ & $24,300,000$ & 0 \\
\hline 138 & Regency of Trenggalek - East Java & $11,750,700$ & 587,535 & $11,163,165$ & $24,300,000$ & 0 \\
\hline 139 & Regency of Ngawi - East Java & $11,700,000$ & 585,000 & $11,115,000$ & $24,300,000$ & 0 \\
\hline 140 & Regency of Pacitan - East Java & $11,534,250$ & 576,713 & $10,957,538$ & $24,300,000$ & 0 \\
\hline 141 & Regency of Magetan - East Java & $11,261,250$ & 563,063 & $10,698,188$ & $24,300,000$ & 0 \\
\hline 142 & Regency of Badung - Bali & $18,213,000$ & 910,650 & $17,302,350$ & $24,300,000$ & 0 \\
\hline 143 & City of Denpasar - Bali & $17,654,000$ & 882,700 & $16,771,300$ & $24,300,000$ & 0 \\
\hline 144 & Regency of Gianyar - Bali & $15,990,000$ & 799,500 & $15,190,500$ & $24,300,000$ & 0 \\
\hline 145 & Regency of Karangasem - Bali & $15,535,000$ & 776,750 & $14,758,250$ & $24,300,000$ & 0 \\
\hline 146 & Regency of Jembrana - Bali & $15,762,500$ & 788,125 & $14,974,375$ & $24,300,000$ & 0 \\
\hline 147 & Regency of Tabanan - Bali & $16,250,000$ & 812,500 & $15,437,500$ & $24,300,000$ & 0 \\
\hline 148 & Regency of Klungkung - Bali & $15,470,000$ & 773,500 & $14,696,500$ & $24,300,000$ & 0 \\
\hline 149 & Regency of Buleleng - Bali & $15,600,000$ & 780,000 & $14,820,000$ & $24,300,000$ & 0 \\
\hline 150 & Regency of Bangli - Bali & $15,366,000$ & 768,300 & $14,597,700$ & $24,300,000$ & 0 \\
\hline 151 & City of Pontianak - West Kalimantan & $15,145,000$ & 757,250 & $14,387,750$ & $24,300,000$ & 0 \\
\hline 152 & City of Makassar - South Sulawesi & $19,500,000$ & 975,000 & $18,525,000$ & $24,300,000$ & 0 \\
\hline
\end{tabular}

